\title{
Review \\ The Evolution of Manufacturing Technology for GaN Electronic Devices
}

\author{
An-Chen Liu ${ }^{1}$, Po-Tsung Tu 1,2, Catherine Langpoklakpam ${ }^{1}$, Yu-Wen Huang ${ }^{1}$, Ya-Ting Chang ${ }^{1}$, An-Jye Tzou ${ }^{3}$, \\ Lung-Hsing Hsu ${ }^{1,2, * \mathbb{D}}$, Chun-Hsiung Lin ${ }^{4, *}$, Hao-Chung Kuo ${ }^{1,5, * \mathbb{C}}$ and Edward Yi Chang ${ }^{4}$
}

1 Department of Photonics, Institute of Electro-Optical Engineering, National Yang Ming Chiao Tung University, Hsinchu 30010, Taiwan; arsen.liou@gmail.com (A.-C.L.); itriA30378@itri.org.tw (P.-T.T.); cath01.ee09@nycu.edu.tw (C.L.); huangwendy227@gmail.com (Y.-W.H.); s922085493@gmail.com (Y.-T.C.)

2 Industrial Technology Research Institute, No. 195, Sec. 4, Chung Hsing Rd., Chutung, Hsinchu 31040, Taiwan

3 Taiwan Semiconductor Research Institute, No. 26, Prosperity Road 1, Hsinchu 30078, Taiwan; jerrytzou.ep00g@gmail.com

4 International College of Semiconductor Technology, National Yang Ming Chiao Tung University, Hsinchu 30010, Taiwan; edc@mail.nctu.edu.tw

5 Semiconductor Research Center, Hon Hai Research Institute, Taipei 114699, Taiwan

* Correspondence: alger.99g@g2.nctu.edu.tw (L.-H.H.); chun_lin@nctu.edu.tw (C.-H.L.); hckuo@faculty.nctu.edu.tw (H.-C.K.); Tel.: +886-3-571-2121 (ext. 31986) (H.-C.K.)

Citation: Liu, A.-C.; Tu, P.-T.; Langpoklakpam, C.; Huang, Y.-W.; Chang, Y.-T.; Tzou, A.-J.; Hsu, L.-H.; Lin, C.-H.; Kuo, H.-C.; Chang, E.Y. The Evolution of Manufacturing Technology for GaN Electronic Devices. Micromachines 2021, 12, 737. https://doi.org/10.3390/mi12070737

Academic Editor: Giovanni Verzellesi

Received: 24 May 2021

Accepted: 8 June 2021

Published: 23 June 2021

Publisher's Note: MDPI stays neutral with regard to jurisdictional claims in published maps and institutional affiliations.

Copyright: (c) 2021 by the authors. Licensee MDPI, Basel, Switzerland. This article is an open access article distributed under the terms and conditions of the Creative Commons Attribution (CC BY) license (https:// creativecommons.org/licenses/by/ $4.0 /)$.
Abstract: GaN has been widely used to develop devices for high-power and high-frequency applications owing to its higher breakdown voltage and high electron saturation velocity. The GaN HEMT radio frequency $(\mathrm{RF})$ power amplifier is the first commercialized product which is fabricated using the conventional Au-based III-V device manufacturing process. In recent years, owing to the increased applications in power electronics, and expanded applications in RF and millimeter-wave (mmW) power amplifiers for 5G mobile communications, the development of high-volume production techniques derived from CMOS technology for GaN electronic devices has become highly demanded. In this article, we will review the history and principles of each unit process for conventional HEMT technology with Au-based metallization schemes, including epitaxy, ohmic contact, and Schottky metal gate technology. The evolution and status of CMOS-compatible Au-less process technology will then be described and discussed. In particular, novel process techniques such as regrown ohmic layers and metal-insulator-semiconductor (MIS) gates are illustrated. New enhancement-mode device technology based on the $\mathrm{p}-\mathrm{GaN}$ gate is also reviewed. The vertical GaN device is a new direction of development for devices used in high-power applications, and we will also highlight the key features of such kind of device technology.

Keywords: gallium nitride; high-electron mobility transistor; CMOS-compatible Au-free process

\section{Introduction}

Gallium nitride $(\mathrm{GaN})$ is a high-potential semiconductor material. It has been used to fabricate high-electron mobility transistors (HEMTs) for applications in power devices and radio frequency (RF) power amplifiers because of its superior material characteristics compared with silicon (Si)-based materials, including a wide bandgap, high breakdown electric field, and high electron saturation velocity, as shown in Figure 1 [1,2].

In 1979, Takashi Mimura invented the gallium arsenide high-electron mobility transistor (GaAs HEMT) [3]. An HEMT uses a heterojunction to enhance electron mobility, thereby increasing the speed of electron transport. A heterojunction with a wider-bandgap Schottky barrier and a lower-bandgap channel can be used to form a modulation-doping structure to spatially separate conducting electrons from their doped impurity atoms. Therefore, a transistor with a high-electron mobility channel can be created (i.e., HEMT). The GaAs HEMT has been widely used in mobile phones, satellite TV receivers, and radar 
equipment [4-6]. The aluminum gallium nitride (AlGaN)/gallium nitride (GaN) heterojunction was first reported in 1991 [7], and the first AlGaN/GaN HEMT was subsequently developed in 1993 [8,9], where superior channel electron mobility was demonstrated. In 2006, the GaN HEMT RF transistor was first produced by Eudyna of Japan [10]. Since then, other companies have also announced various GaN HEMT products for RF applications. The GaN HEMT can be operated at $50 \mathrm{~V}$ with an output power over $200 \mathrm{~W}$ for mobile communication applications using silicon carbide (SiC) as the substrate [11-13]. In 2001, a research team from the University of California at Santa Barbara reported a GaN HEMT for power switch application fabricated on $\mathrm{SiC}$, which possessed a breakdown voltage higher than 1000 V [14]. Since then, GaN HEMTs have been studied intensively on Si substrates for their low cost, high volume, and high-performance power switch applications. After years of development, the state-of-the-art GaN HEMT power devices on Si can be operated at a breakdown voltage higher than $1200 \mathrm{~V}[15,16]$.

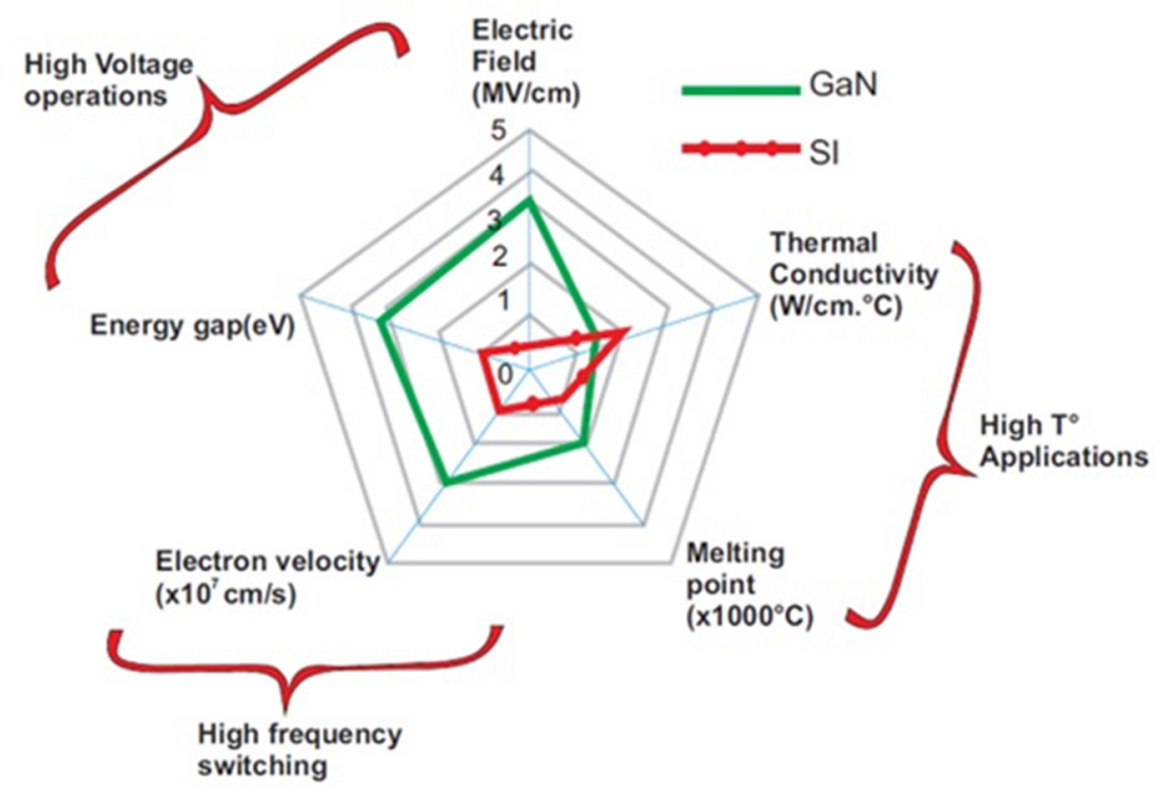

Figure 1. Differences in material properties between GaN and Si [2]. (Data from [2]).

Unlike the GaAs HEMT counterpart which needs to have a doping layer in the widebandgap AlGaAs barrier, GaN HEMTs do not need a doping layer in the wide-bandgap $\mathrm{AlGaN}$ barrier layer. Due to the polarization effects of the hexagonal wurtzite structure of $\mathrm{AlGaN}$ and $\mathrm{GaN}$ materials, the heterostructure of $\mathrm{AlGaN} / \mathrm{GaN}$ has a high-density two-dimensional electron gas (2D electron gas; 2DEG) formed at the interface between $\mathrm{AlGaN}$ and $\mathrm{GaN}$ [17]. These polarization effects include two mechanisms, one is spontaneous polarization $\left(\mathrm{P}_{\mathrm{SP}}\right)$ and the other is piezoelectric polarization $\left(\mathrm{P}_{\mathrm{PE}}\right)$. Spontaneous polarization $\left(\mathrm{P}_{\mathrm{SP}}\right)$ is induced because gallium atoms in the non-centrosymmetric wurtzite structure do not locate at the center of the mass with respect to nitrogen atoms. On the other hand, the piezoelectric polarization effect $\left(\mathrm{P}_{\mathrm{PE}}\right)$ is induced because of the stack of two lattice-mismatched wurtzite III-nitride materials. Polarization charges are formed due to the mismatch strain at the heterogeneous junction, as shown in Figure 2 [18].

The most commonly used GaN HEMT is an AlGaN/GaN heterostructure. The typical thickness of AlGaN is around 20-25 nm, and the thickness of the GaN channel and buffer layer is around 1-5 $\mu \mathrm{m}$ depending on the requirement of the breakdown voltage [15]. According to the energy band structure of the GaN HEMT, there is a potential energy well at the junction of $\mathrm{AlGaN}$ and $\mathrm{GaN}$, and there will be a transportable energy state formed by the accumulation of electrons in this energy well, as shown in Figure $3[17,19]$. Figure 3a shows the charge accumulated in the potential well as $V_{G}=0$, and Figure $3 b$ indicates that the accumulated charges are depleted with $\mathrm{V}_{\mathrm{G}}<\mathrm{V}_{\mathrm{T}}<0$. 


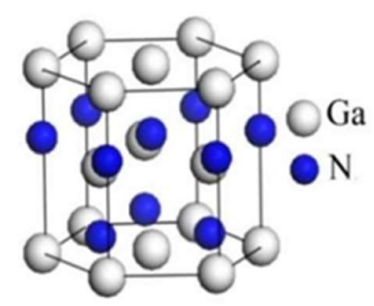

Figure 2. Gallium nitride wurtzite structure [18]. (Data from [18]).
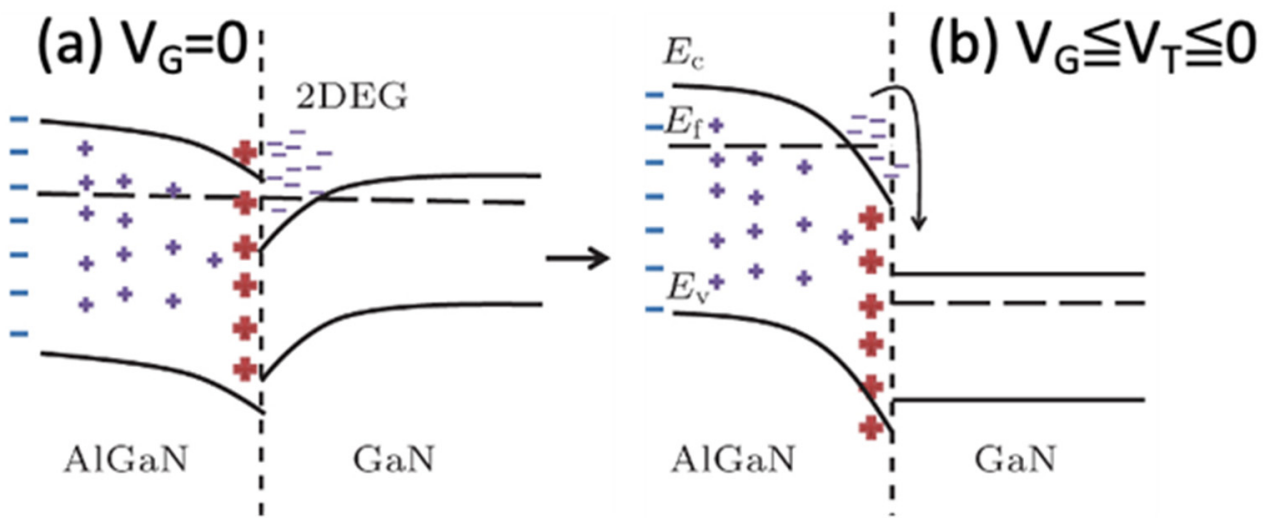

Figure 3. (a) The charge accumulation at the potential well as $\mathrm{V}_{\mathrm{G}}=0$, and (b) the accumulated charges depleted as $\mathrm{V}_{\mathrm{G}}<\mathrm{V}_{\mathrm{T}}<0$ [19]. Figure reproduced with permission from Chin. Phys. B.

In addition to the AlGaN/GaN HEMT, the InAlN/GaN heterostructure also attracts a lot of attention $[20,21]$. For AlGaN grown on $\mathrm{GaN}$, the lattice mismatch restricts the AlGaN content and thickness. Figure 4 demonstrates the bandgaps versus lattice parameters of AlN-GaN-InN compounds [22]. InAlN, with around $18 \%$ In, is lattice-matched with GaN, and its wide bandgap makes it an ideal barrier. In the meantime, the heterostructure of InAlN/GaN possesses high accumulation charges at the interface owing to the larger difference in spontaneous polarization between the two layers. In Section 2.1, we will further discuss the current development of the GaN epitaxial structure.

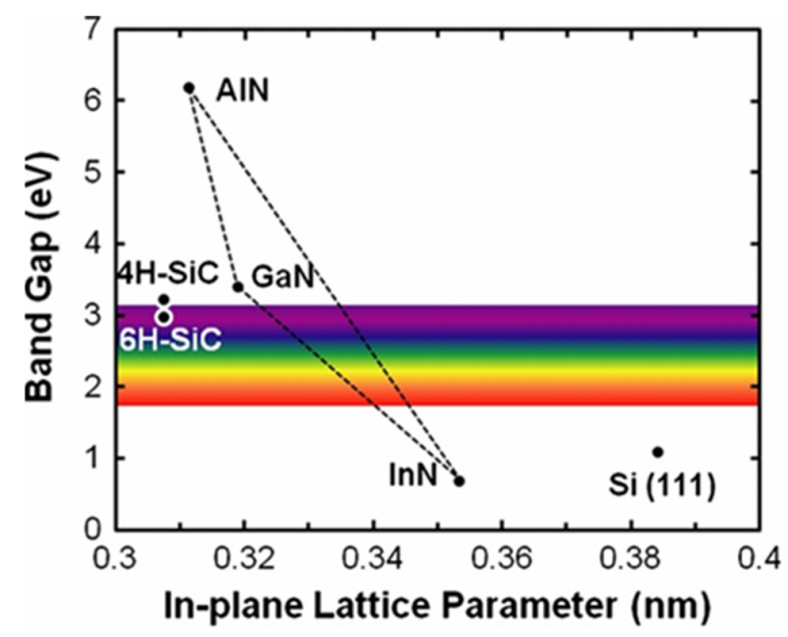

Figure 4. Lattice parameters and band gap for GaN-AlN-InN alloys [22]. (Data from [22]).

\subsection{Radio Frequency HEMT Device Applications}

In the past two decades, mobile communication technology has developed rapidly from 2G in 1990 to the introduction of $3 \mathrm{G}$ in 2000, and then the deployment of 4G service in 2011 until today [23-29]. Under the trend of continuous innovation and service demand, 
5G was launched recently in 2019-2020. Global research institutions have also begun to invest in research and development for 5G +/ 6G technologies. Currently, 5G is still operated below $6 \mathrm{GHz}$ which is relatively similar to $4 \mathrm{G}$. High-band $5 \mathrm{G}$ operating at $\mathrm{mmW}(28-40 \mathrm{GHz})$ is still in development and is expected to be deployed in the near future $[23,27,30]$. The GaN HEMT that can be applied in high-frequency power amplifiers has been regarded as an important device technology by various manufacturers. Figure 5 shows the breakdown voltage versus current gain cut-off frequency $\left(\mathrm{f}_{\mathrm{T}}\right)$ of different types of devices [31,32]. The GaN HEMT shows the best capabilities, combining a high voltage, high power, and high speed. Moreover, the GaN-on-Si technology that can greatly reduce production costs and is more suitable for high-volume production has attracted a lot of attention [33]. In the past, the GaN HEMT was mainly fabricated on $\mathrm{SiC}$ substrates for highfrequency applications owing to the better quality of epitaxy and the better heat dissipation. With improved techniques in epitaxial growth and layout optimization for GaN-on-Si devices, several manufactures have announced the launch of the mass production of GaN-on-Si technology for high-frequency applications [34].

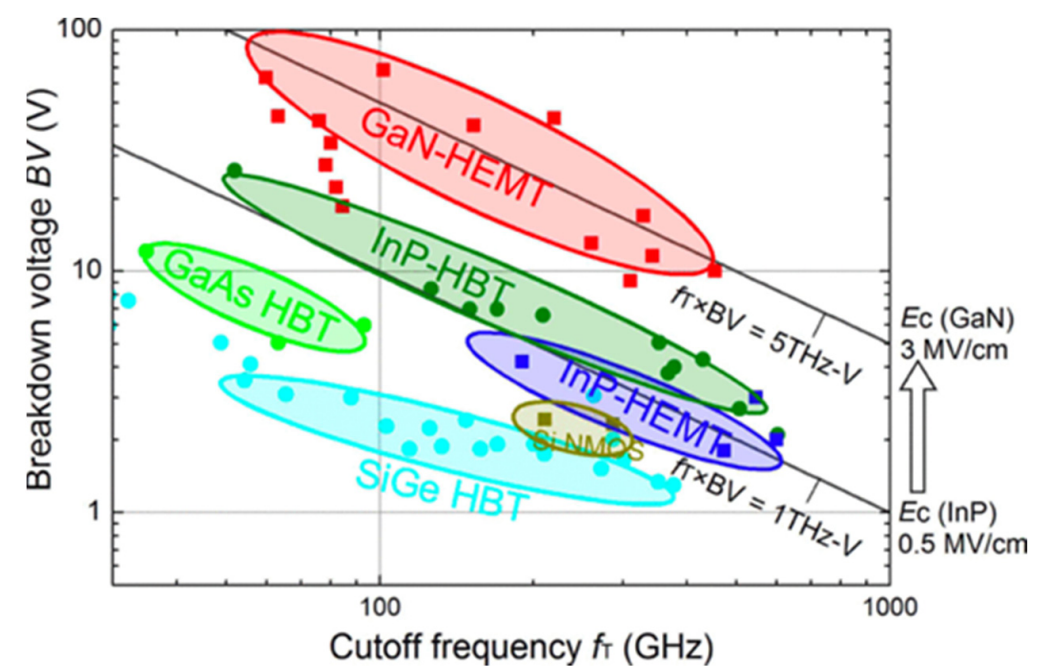

Figure 5. Comparison of breakdown voltage and cut-off frequency among various high-speed device technologies [32]. Figure reproduced with permission from IEEE Trans. Electron Devices.

In view of the applications in $4 \mathrm{G}$ to $5 \mathrm{G}$ base stations, outdoor WiFi, millimeter-wave $(\mathrm{mmW})$ small cells, and other high-data rate wireless communication applications, increasing the transmit power and efficiency is an important issue. At present, RF and $\mathrm{mmW}$ power amplifiers in the market mainly use SiGe- or GaAs-based transistors. However, due to the constraint in the breakdown voltage, individual power amplifiers made of these materials cannot provide an efficient output power in the $\mathrm{mmW}$ band [31]. Technologies such as phased array antennas are needed to achieve the overall required transmission power [35]. However, too many phase array antennas will cause problems such as narrow beams and manufacturing complexity. Therefore, further improvement in the output power and efficiency of the devices for power amplifiers has become an important issue.

In recent years, a GaN HEMT with a maximum oscillating frequency $\left(f_{\max }\right)$ /current gain cut-off frequency $\left(f_{t}\right)$ of up to $300 \mathrm{GHz}$ has been demonstrated [36]. An MMIC fabricated using $\mathrm{GaN}$ technology with an operating frequency up to the $\mathrm{G}$ band was also presented. The output power and gain can reach around $16 \mathrm{dBm}$ and $12 \mathrm{~dB}$ at $181 \mathrm{GHz}$ with $5.5 \%$ of power-added efficiency (PAE) [37]. For $5 \mathrm{G}$ operation, an output power density of $10 \mathrm{~W} / \mathrm{mm}$ at sub- $6 \mathrm{GHz}$ and an output power density of $6 \mathrm{~W} / \mathrm{mm}$ at $40 \mathrm{GHz}$ were achieved [38]. Moreover, Intel has demonstrated a GaN MOSHEMT with $\mathrm{f}_{\mathrm{t}} / \mathrm{f}_{\max }$ reaching $200 / 350 \mathrm{GHz}$ and a high $\mathrm{mmW}(28 \mathrm{GHz})$ output power of $19.5 \mathrm{dBm}$ fabricated on Si. Three-dimensional integration with CMOS has also been reported [33,39]. 


\subsection{Power HEMT Device Applications}

For power device applications, GaN HEMTs have shown low on-resistance to greatly reduce the conduction loss of the switch with a high breakdown voltage. Moreover, GaN power devices have lower parasitic capacitance, which can provide faster switching than silicon power transistors, meaning they have a much lower energy loss. The relation between the switching speed and energy loss of power switches is depicted in Figure 6a. The switching speed of GaN is faster; hence, the switching loss of the GaN HEMT is much less than that of $\mathrm{Si}$, as indicated by Figure $6 \mathrm{~b}$ [40]. Therefore, the GaN HEMT has great potential in high-speed, high-power switch applications.

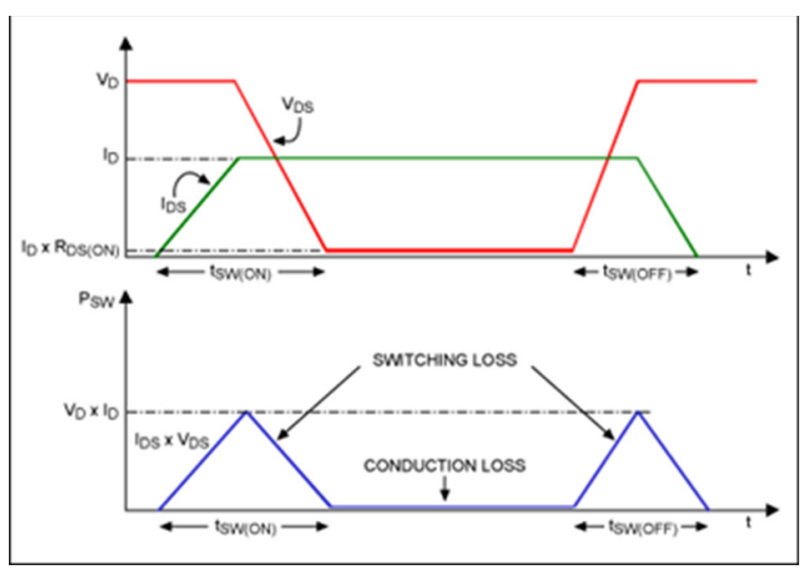

(a)

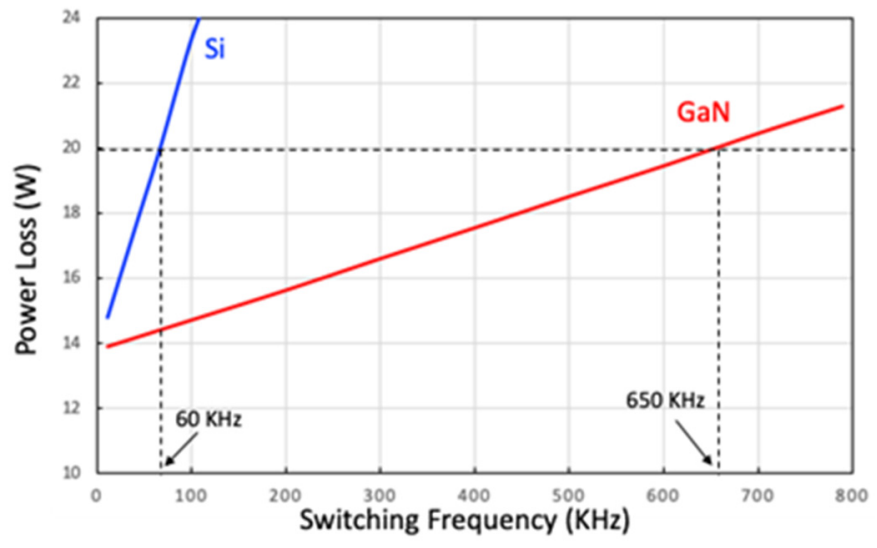

(b)

Figure 6. (a) Relation between switching speed and energy loss for a power switch, and (b) the lower power loss of GaN compared with Si [40]. Figure reproduced with permission from IEEE 2016 10th International Conference on Compatibility, Power Electronics and Power Engineering.

Overall speaking, the GaN-on-Si HEMT is still inferior to SiC devices in terms of high-voltage and high-power performances owing to the higher defects in epitaxy and the worse thermal dissipation capability of Si substrates. However, $\mathrm{GaN}$ is expected to replace Si-based diodes, MOSFETs, and other power components in the low- and medium-power fields in the future. It is predicted that $\mathrm{SiC}$ has an advantage over $\mathrm{GaN}$ above $900 \mathrm{~V}$; however, $\mathrm{GaN}$ is very competitive for operating voltages below $1000 \mathrm{~V}$ due to the benefits of a low switching loss and lower cost [41].

Currently, the fastest-growing GaN power device application is GaN fast chargers, and various products have been brought to the market. At present, fast chargers with power ranging from $65 \sim 125 \mathrm{~W}$ have gradually become mainstream products because the fast charger made by a GaN power IC is small in size, easy to carry, capable of high-power operation, has a higher energy efficiency, and is cost-effective.

\subsection{Process Development (From Au-Based to Au-Free $\mu S$-Coppatible)}

Traditionally, the manufacturing of GaN HEMT devices is based on Au-based metallization schemes, including ohmic contact metals and Schottky metal gates. In the past decade, due to the rapid development of GaN epitaxy on silicon substrates, the development of complementary metal-oxide-semiconductor (CMOS)-compatible fabrication processes for GaN-on-Si devices has increased sharply and gradually matured. There are several major changes in fabrication techniques as compared to the CMOS-compatible processes with conventional III-V processes.

For instance, CMOS-compatible processes usually need to have a planarized structure. Therefore, ion implantation of nitrogen or other inert elements to amorphized non-active regions to achieve device isolation instead of etching the active layers (i.e., "mesa etching") can be a preferred method. On the other hand, most traditional III-V devices use Au-based metallization schemes that are incompatible with the CMOS fabrication process. To be 
compatible with the CMOS fabrication process, the commonly used $\mathrm{Ti} / \mathrm{Al} / \mathrm{Ni} / \mathrm{Au}$ ohmic contact metal stack can be changed to $\mathrm{Ti} / \mathrm{Al} / \mathrm{Ni} / \mathrm{TiN}$ [42]. Moreover, a TiN diffusion barrier/Schottky metal and a $\mathrm{Cu}$ or $\mathrm{Al}$ conductor layer can be used for the metal gate instead of a Ni Schottky metal and Au conductor layer [43].

In this article, we will first describe the key steps in traditional Au-based manufacturing processes for GaN HEMT devices including the ohmic contact at the source/drain area, and the Schottky metal gate. Then, the evolution of the Au-free process flow for CMOScompatible GaN technology will be illustrated. We will also discuss the new developments in structures and materials used in CMOS-compatible manufacturing processes in ohmic contact formation and gate structures $[44,45]$.

\section{Conventional GaN HEMT Technology}

\subsection{Epitaxy}

In recent years, the epitaxial quality of $\mathrm{GaN}$ and its doping technology have become matured and resulted in the fast development of high-power and high-frequency electronic devices. Due to the lack of high-quality and large-size GaN substrates on the market, GaN heterostructures are mainly grown on silicon (Si), sapphire (Sapphire), or silicon carbide (SiC) substrates.

During the epitaxy process, the mismatch in the lattice and thermal expansion coefficient between $\mathrm{GaN}$ and the substrates is the key factor to be concerned about. Listed in Table 1 are the physical parameters of the commonly used substrates [46]. The lattice constant and thermal expansion coefficient mismatch between the $\mathrm{SiC}$ substrate and the $\mathrm{GaN}$ is the smallest; therefore, the quality of the $\mathrm{GaN}$ epitaxy grown on $\mathrm{SiC}$ is the best. Moreover, the $\mathrm{SiC}$ substrate has very good thermal conductivity, meaning it can effectively remove the heat generated by GaN components during high-frequency and high-power operations to enhance reliability. High-quality GaN-based materials coupled with a substrate with good thermal conductivity could improve the overall characteristics of the device. However, the $\mathrm{SiC}$ substrate is an expensive substrate that is difficult to produce; therefore, the cost-effective GaN-on-Si technology becomes an attractive choice for many manufacturers. However, due to the larger mismatch in the lattice constant and thermal expansion between $\mathrm{Si}$ substrates and $\mathrm{GaN}$, it is more difficult to grow high-quality $\mathrm{GaN}$ on $\mathrm{Si}$ substrates. Usually, it is necessary to use a thicker or complex buffer layer structure [47-49].

Table 1. The lattice and thermal mismatch of $\mathrm{Si}$, SiC, Sapphire, AlN, and GaN [46].

\begin{tabular}{cccccc}
\hline Mismatch & Si & SiC & Sapphire & AlN & GaN \\
\hline Crystal Structure & FCC & HCP & HCP & HCP & HCP \\
Lattice Constant $(\AA)$ & 5.43 & 3.08 & 4.758 & 3.112 & 3.189 \\
Lattice Mismatch $(\%)$ & -16.9 & 3.5 & 16.08 & 2.4 & - \\
Thermal Expansion $\left(10^{-6} \mathrm{~K}\right)$ & 3.59 & 4.3 & 7.3 & 4.15 & 5.59 \\
Thermal Mismatch $(\%)$ & 55 & 30 & -23 & 34 & - \\
\hline
\end{tabular}

The design and growth of buffer layers are very critical. The characteristics of the GaN HEMT, especially the breakdown voltage, are affected by the quality and resistivity of the underlying buffer layer. The GaN buffer layer under the channel needs higher resistivity to prevent the DC leakage current and AC coupling. Since undoped GaN is typically n-type, adding a p-type dopant is required to obtain a highly resistive buffer. A commonly used p-type dopant is $\mathrm{Mg}$; however, the memory effect of $\mathrm{Mg}$ is very strong [50], and it will affect the properties of the subsequent AlGaN/GaN epitaxy. Thus far, Fe and carbon are used as p-type dopants for the buffer layer. However, Fe dopants still have the issue of a memory effect on the MOCVD growth, and it is not easy to obtain an abrupt interface $[51,52]$. Carbon is a more attractive p-type dopant for the buffer layer. It does not have a strong memory effect, and its concentration and the breakdown voltage of the buffer layer can be adjusted by changing the epitaxial conditions, as shown in Figure 7 [53,54]. On the other hand, a buffer layer has to be designed to release stress and make the surface 
flat. Typical structures include a graded AlGaN buffer [55], a GaN/AlGaN superlattice buffer [56], low-T GaN, or low-T GaN with an AlN insertion [57]. For the growth of GaN on $\mathrm{Si}$ substrates, AlN nucleation and a buffer layer have to be grown to avoid interaction between $\mathrm{Ga}$ and $\mathrm{Si}$ at high growth temperatures.

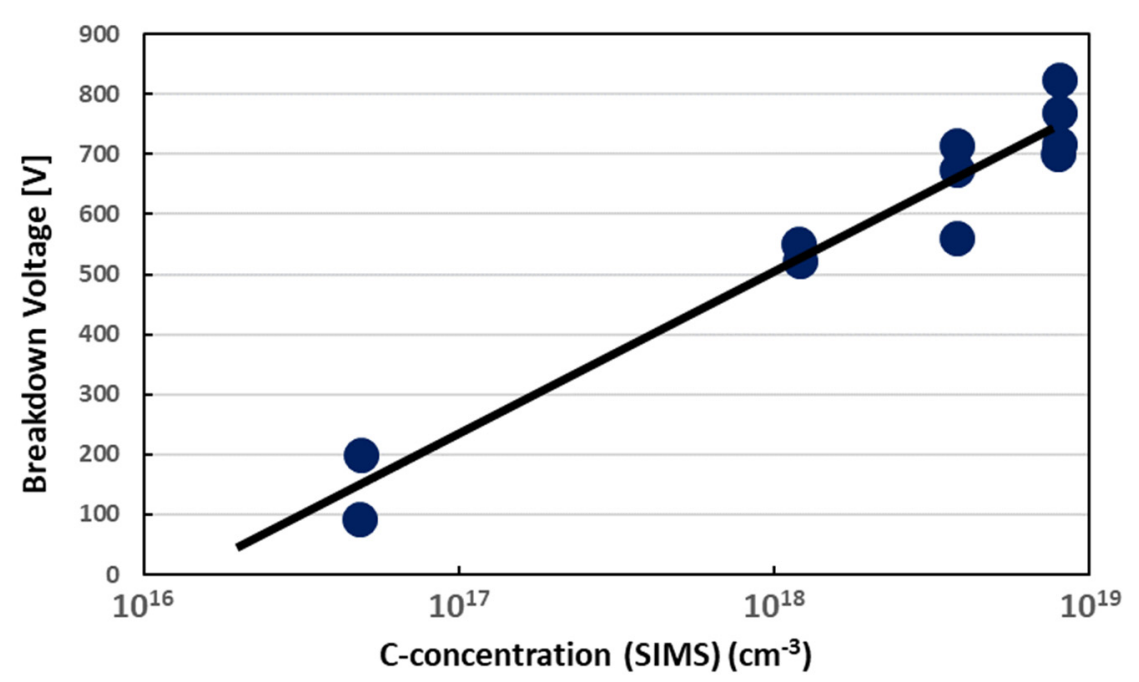

Figure 7. The relationship between breakdown voltage and Carbon doping concentrations in the GaN buffer layer [53]. Figure reproduced with permission from J. Cryst. Growth.

The typical top barrier layer for GaN HEMTs is AlGaN or InAlN, as described in Section 1. While the AlGaN barrier layer is very mature, the thickness and $\mathrm{Al}$ content have restrictions due to the lattice mismatch with GaN. As the thickness becomes too thin, the charge in the channel would decline due to insufficient piezoelectric polarization. On the contrary, defects would appear as the thickness exceeds the critical thickness. The lattice-matched InAlN (18\% In) barrier has stronger spontaneous polarization to induce a much higher channel charge than AlGaN [20]. Nevertheless, phase separation of $\operatorname{InN}$ and AlN could occur during MOCVD growth and result in a high gate leakage current, as the TEM image shows in Figure 8 [58-60]. Careful optimization of the growth condition has to be carried out to avoid phase separation.

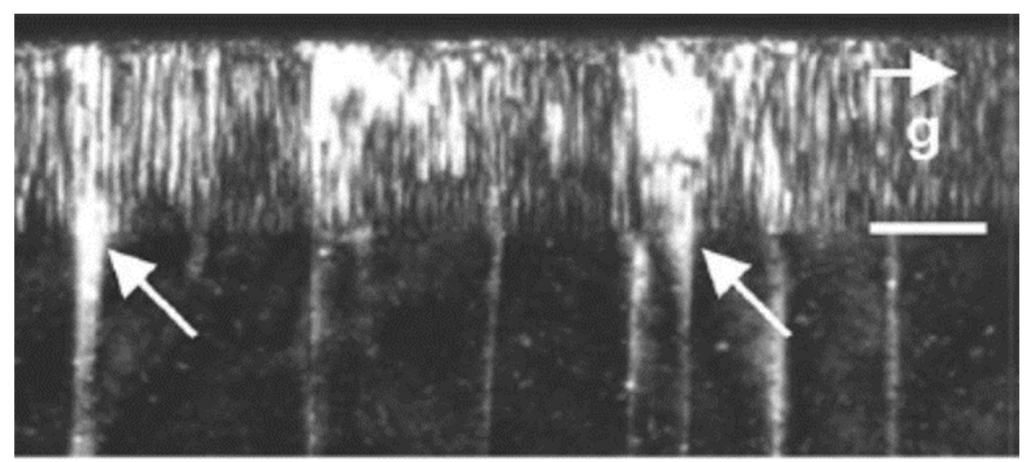

Figure 8. Cross-sectional TEM images of InAlN layer showing phase separation [58]. Figure reproduced with permission from Appl. Phys. Lett.

\subsection{Ohmic Contact}

An ohmic contact is a type of metal/semiconductor contact formed at the source/drain region. The interface has to be heavily doped to form a very thin energy barrier to allow for the tunneling of carriers through the interface to obtain low contact resistance. In the traditional III-V-based process, the most commonly used ohmic contact metals for GaN are diffusion-type multi-layer ohmic contact metals based on titanium (Ti)/aluminum 
(Al). Then, nickel (Ni)/gold ( $\mathrm{Au}$ ) is stacked on $\mathrm{Ti} / \mathrm{Al}$ to form a thick conductive metal layer [61]. For a CMOS-compatible process, $\mathrm{Ni} / \mathrm{Au}$ is not used, but $\mathrm{TiN}, \mathrm{Al}$, or $\mathrm{Cu}$ is used for the thick conductive metal layer. Generally, there is a diffusion barrier layer (i.e., Ni) between the thick conductive metal layer and the $\mathrm{Ti} / \mathrm{Al}$ ohmic contact metal, meaning the top conductive layer does not affect the characteristics of the GaN ohmic contact interface.

The role of $\mathrm{Ti} / \mathrm{Al}$ diffusion-type ohmic contact metals in the process of reducing the interface energy barrier is explained by several studies in the literature [61-64]. When rapid thermal annealing (RTA) is used, and the maximum temperature is raised to above $800{ }^{\circ} \mathrm{C}$, $\mathrm{Ti} / \mathrm{Al}$ can diffuse into the GaN layer and form a uniform TiAlN alloy. The process can cause nitrogen vacancies to be generated in the crystal lattice. Nitrogen vacancies in GaN act as the n-type dopants to enhance the n-type characteristics of GaN to further reduce the resistance. Figure 9a shows the TEM images formed by annealing a $\mathrm{Ti} / \mathrm{Au} / \mathrm{Al} / \mathrm{Ni} / \mathrm{Au}$ ohmic contact metal at $850{ }^{\circ} \mathrm{C}$ [63]. Figure $9 \mathrm{~b}$ exhibits the effect of $\mathrm{N}$ vacancy formation on the interfacial band structure of GaN [65].
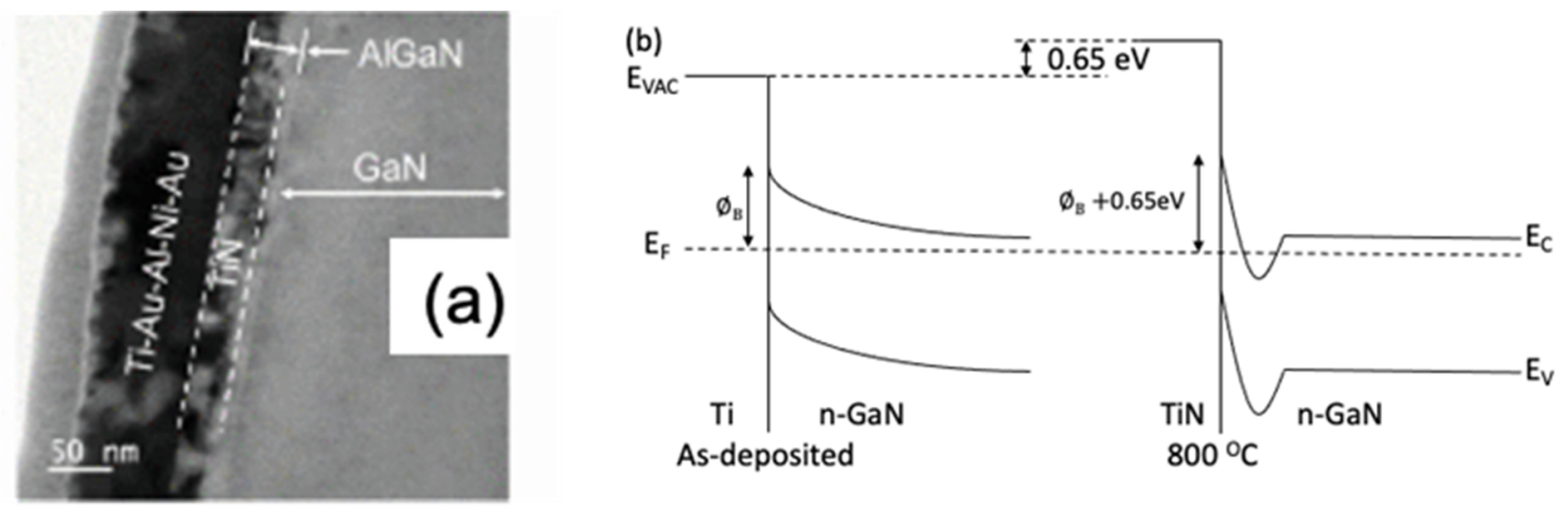

Figure 9. (a) TEM images of $\mathrm{Ti} / \mathrm{Au} / \mathrm{Al} / \mathrm{Ni} / \mathrm{Au}$ structure after alloying [63], and (b) band diagram before/after alloying [65]. Figure reproduced with permission from IEEE Electron Device Lett. \& AIP Publishing.

As shown in Figure 10, the contact resistivity of GaN can reach $5 \times 10^{-6} \Omega \mathrm{cm}^{2}$ after annealing a Ti/Al-based $(\mathrm{Ti} / \mathrm{Al}=0.43)$ ohmic contact metal at $800{ }^{\circ} \mathrm{C}$ [66]. The effect of the ratio of $\mathrm{Ti}$ and $\mathrm{Al}$ thicknesses is also discussed in the literature [67]. By summarizing the studies from many research works, it can be shown that $\mathrm{Ti} / \mathrm{Al}$ ohmic contact metals are, thus far, the most stable ohmic contacts for n-type GaN, and the major factors that affect the contact resistances are the $\mathrm{Ti} / \mathrm{Al}$ ratio and the annealing conditions. As long as the top conductive Au metal is well separated from the Ti/Al layer by a diffusion barrier, the contact resistivity is not affected by the Au conductive layer $[66,67]$.

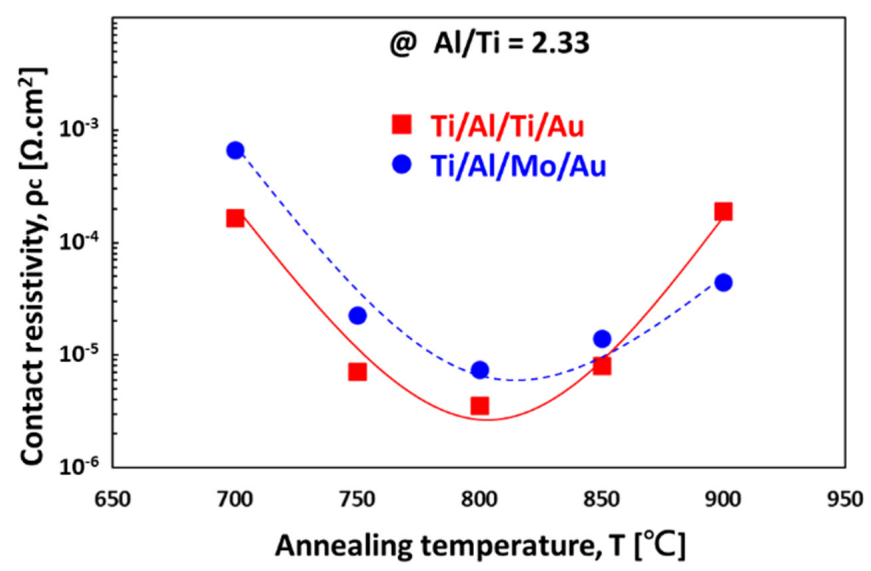

Figure 10. Ti/Al-based ohmic contacts on AlGaN/GaN HEMT as a function of annealing temperature [66]. (Data from [66]). 


\subsection{Schottky Metal Gate}

The choice of gate metal also has significant impacts on the performance and reliability of GaN HEMTs. In the structure of a typical GaN HEMT, there is a wide-bandgap AlGaN barrier layer between the gate metal and the GaN channel. The gate metal forms a Schottky contact on the $\mathrm{AlGaN}$ barrier layer which can control the polarization charge density at the $\mathrm{AlGaN} / \mathrm{GaN}$ interface. The charge density of the heterostructure and the drain current is controlled by modulating the Schottky contact with the applied gate voltage. An excessive gate leakage current is not allowed for HEMT devices because it could result in undesired power consumption at the gate or incomplete channel closure. As most GaN HEMTs are "normally on" devices owing to the intrinsic characteristic of the AlGaN/GaN heterostructure, the drain current of GaN HEMTs has to be turned off by setting the Schottky gate diode at a reversed bias. As shown in Figure 11, Pd, Ni, and Pt are reported to be suitable gate metals since the leakage currents of these metals are the smallest when the GaN Schottky gate diodes are negatively biased [68].

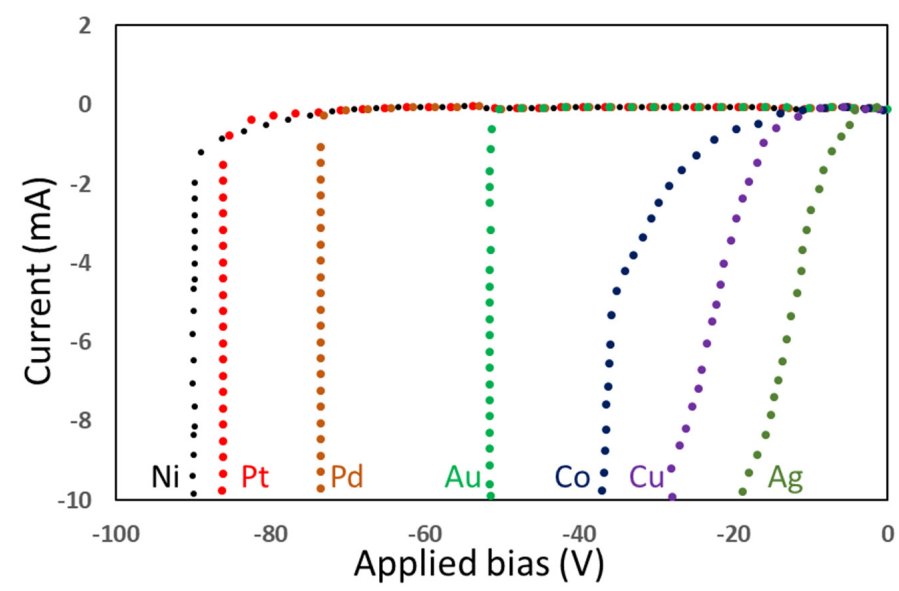

Figure 11. IV characteristic diagram of different metals under reverse bias [68]. (Data from [68]).

On the other hand, the channel temperature can be high during the on-state operation of a power device. Therefore, high thermal stability is required for the selected gate metal. Ni has shown excellent stability [69,70]; thus, Ni/ Au is currently one of the most commonly used gate metals. $\mathrm{WN}$ is another gate metal showing good stability and low leakage. Researchers found that a WN gate can be formed by annealing a W gate in a $\mathrm{N}_{2}$ atmosphere [71]. In addition, metal-insulator-semiconductor (MIS) gates are adopted to more effectively reduce gate leakage. The MIS-HEMT structure will be discussed in more detail in Section 3.2.

\section{CMOS-Compatible Au-Free GaN Technology}

In this section, we will discuss the new developments in structures and materials for CMOS-compatible process technology in the ohmic contact process and gate process.

Traditional III-V power semiconductor devices use Au in the ohmic metal, gate metal, and interconnect. The evaporation/lift-off process is used to fabricate the metallization structure, but it is not compatible with the CMOS production line. Metallization of CMOS chips usually adopts interlevel dielectrics to define and isolate metal lines. Metal is then filled into the desired trench areas, and the metal deposited at undesired areas is removed by etching or CMP processes. The typical process flow of a CMOS-compatible process is depicted in Figure 12. The commonly used metals are $\mathrm{Ti}$, TiN, $\mathrm{Al}, \mathrm{Cu}, \mathrm{W}$, or TaN. Moreover, most manufacturers are in the process of scaling up the GaN production wafer size to $200 \mathrm{~mm}$ or $300 \mathrm{~mm}$. Therefore, major companies (for example, Intel, IMEC) have invested in the development of a gold-free process [72-74]. 


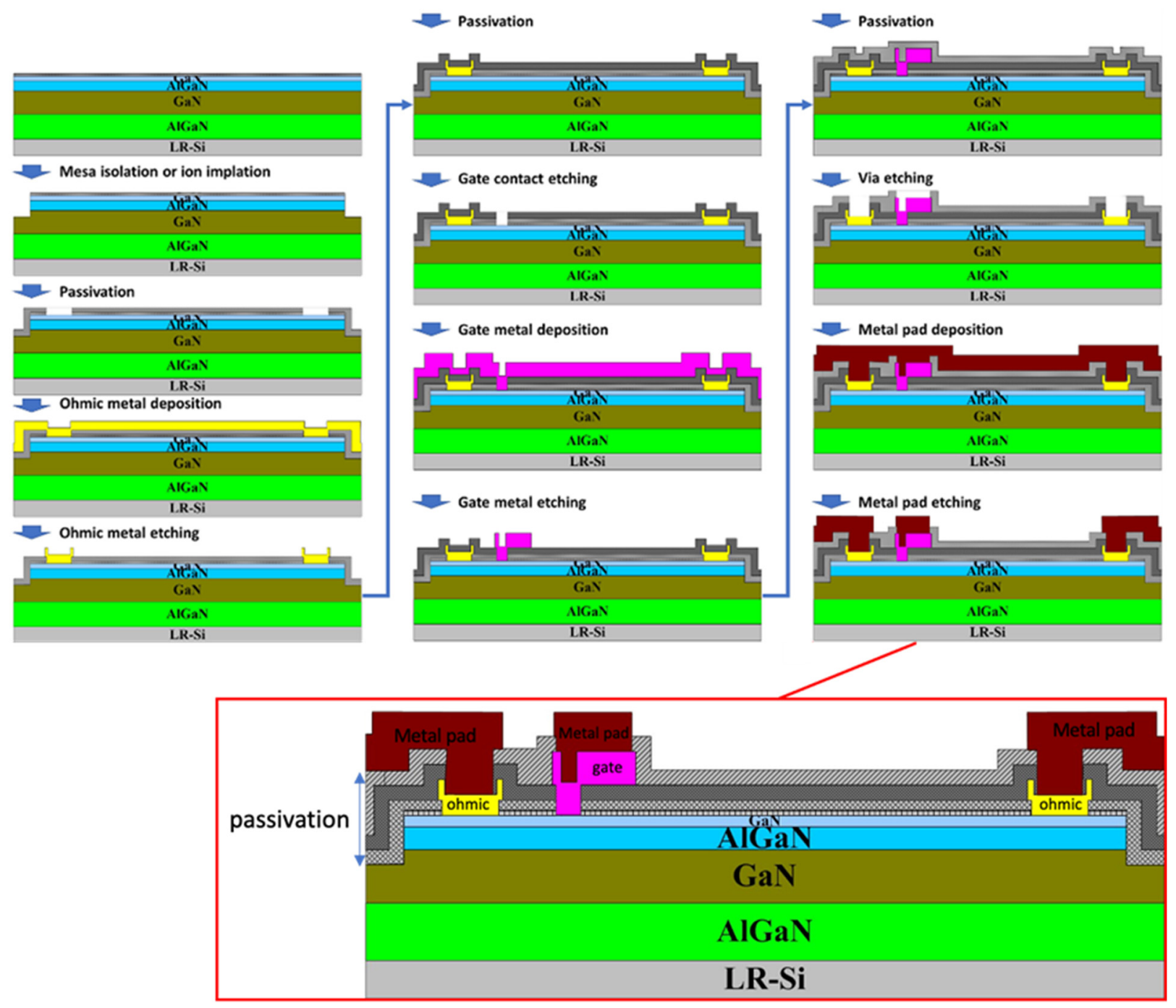

Figure 12. Au-free CMOS-compatible process.

\subsection{Ohmic Contact}

Traditional III-V devices mostly use Au-based metallization schemes that are incompatible with CMOS. The commonly used $\mathrm{Ti} / \mathrm{Al} / \mathrm{Ni} / \mathrm{Au}$ ohmic contact metal for $\mathrm{GaN}$ can be replaced by an MOS-compatible metal stack such as $\mathrm{Ti} / \mathrm{Al} / \mathrm{Ti} / \mathrm{TiN}$. A Aubased $\mathrm{Ti} / \mathrm{Al} / \mathrm{Ni} / \mathrm{Au}$ ohmic contact metal after high-temperature rapid thermal annealing $\left(800 \sim 900{ }^{\circ} \mathrm{C}\right)$ usually shows a rough surface roughness, as shown in Figure 13a. After high-temperature annealing, the upper $\mathrm{Au}$ layer and $\mathrm{Al}$ will react and form a rough surface [75]. The rough ohmic metal surface may affect lithography alignment and subsequent integration. As shown in Figure 13b, the Au-free $\mathrm{Ti} / \mathrm{Al} / \mathrm{Ti} / \mathrm{TiN}$ ohmic metal still shows a smooth surface and exhibits low contact resistivity of $1 \times 10^{-5} \Omega \mathrm{cm}^{2}$ after $950{ }^{\circ} \mathrm{C}$ high-temperature annealing. 

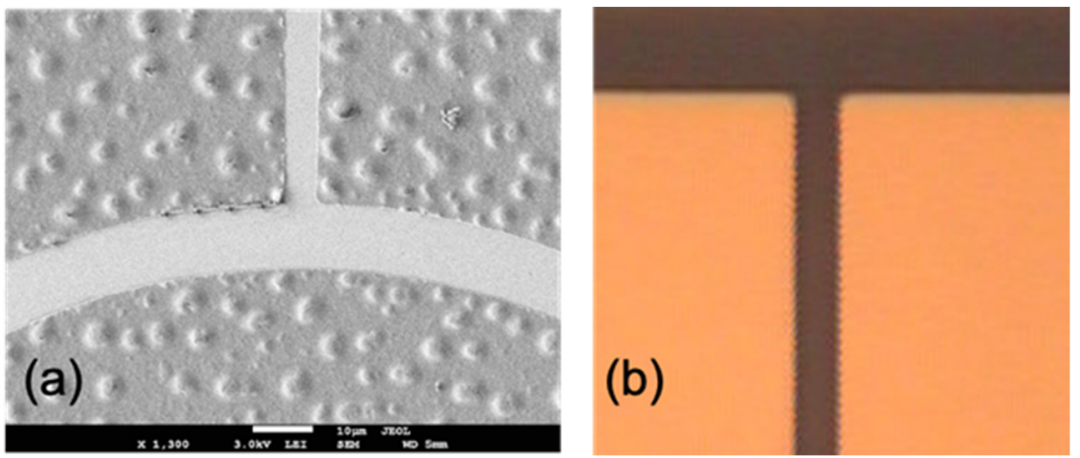

Figure 13. SEM image of (a) Au-based $\mathrm{Ti} / \mathrm{Al} / \mathrm{Ni} / \mathrm{Au}$ ohmic contact annealed at $900{ }^{\circ} \mathrm{C}$ [75], and (b) Au-free ohmic contact $(\mathrm{Ti} / \mathrm{Al} / \mathrm{Ti} / \mathrm{TiN})$ annealed at $950^{\circ} \mathrm{C}$. Figure reproduced with permission from AIP Publishing.

In addition, the formation of ohmic contacts to GaN usually relies on metal diffusion to form a nitrogen vacancy-rich heavily n-doped interface, as described in Section 2.2. However, the diffusion of an ohmic metal through the $\mathrm{AlGaN}$ barrier layer requires annealing at a relatively high temperature $\left(>800{ }^{\circ} \mathrm{C}\right)$. One method to reduce the alloying temperature is to perform the $\mathrm{AlGaN}$ recess etch at the ohmic contact area before the $\mathrm{Ti} / \mathrm{Al}$ ohmic metal is deposited. Figure 14 shows the $R_{c}$ reduction of a device with an $\mathrm{AlGaN}$ recess etched at the ohmic region [72], and the $\mathrm{Ti} / \mathrm{Al} / \mathrm{Ti} / \mathrm{TiN}$ ohmic contact metal alloyed at $550{ }^{\circ} \mathrm{C}$ exhibits excellent contact resistivity.

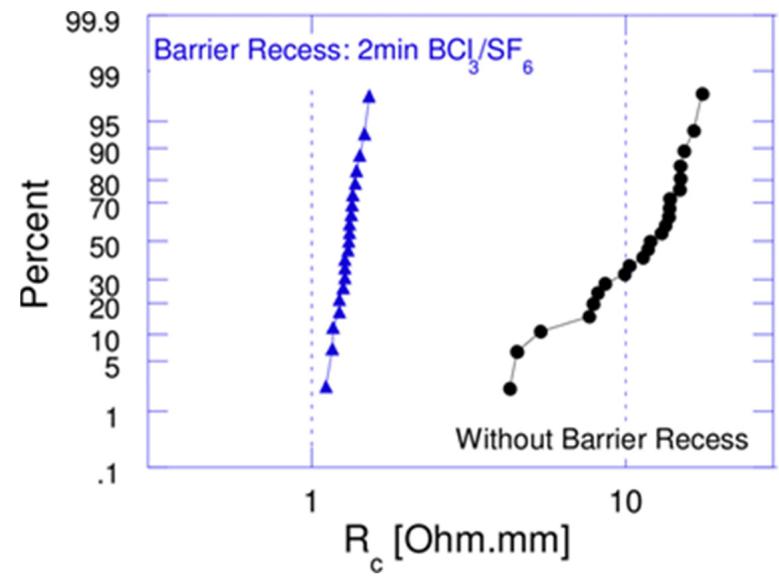

Figure 14. $R_{C}$ distributions of $200 \mathrm{~mm}$ GaN HEMT wafers with and without AlGaN barrier recess annealed at $550{ }^{\circ} \mathrm{C}$ [72]. Figure reproduced with permission from IEEE 2012 24th International Symposium on Power Semiconductor Devices and ICs.

In addition to the surface morphology, the line edge is usually not very smooth after the high-temperature diffusion process. Moreover, it is desired to further reduce the contact resistivity of the ohmic contact to GaN. Regrowth of $n+\mathrm{GaN}$ at the ohmic contact area is a feasible method to further reduce the contact resistance and enable non-alloy ohmic contact to obtain a better surface morphology and interface [76-79]. After AlGaN recess etching is performed at the ohmic contact region, an n-type heavily doped GaN layer is epitaxially grown at the ohmic contact region by MOCVD. Then, $\mathrm{Ti} / \mathrm{Al}$ or TiN is deposited as a non-alloy ohmic contact metal $[41,80-83]$. Several research groups have reported promising results, and a contact resistivity as low as $1.6 \times 10^{-5} \Omega \mathrm{cm}^{2}$ can be achieved [84]. Figure 15 [85] is a STEM micrograph showing the good epitaxial quality of a regrown ohmic layer. 


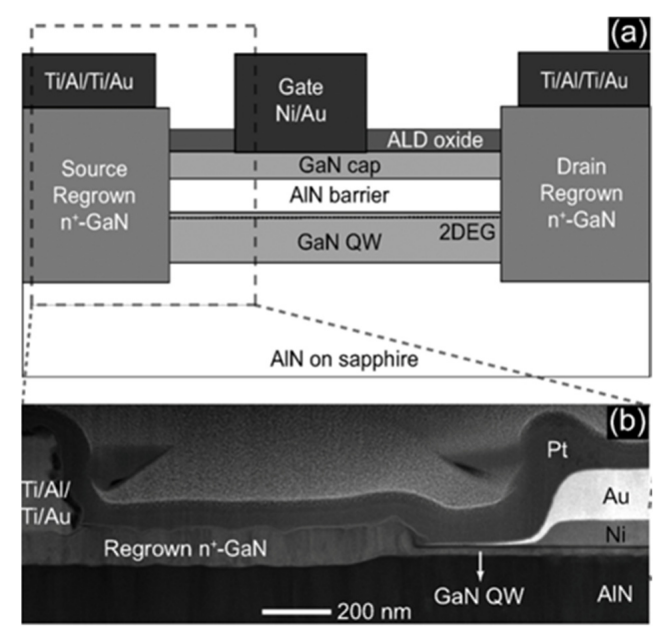

Figure 15. (a) Device structures of GaN HEMT with regrown ohmic layer. (b) STEM image showing regrown GaN connected to the GaN QW channel [85]. Figure reproduced with permission from IEEE Electron Device Lett.

Using ion implantation and laser annealing technology to form non-alloy ohmic contacts on GaN was reported recently. The power density of the pulsed laser annealing is optimized to activate the $\mathrm{Si}$ ion-implanted $\mathrm{GaN}$, and then the $\mathrm{Ti} / \mathrm{Al} / \mathrm{Ni} / \mathrm{Au}$ ohmic is annealed at $500{ }^{\circ} \mathrm{C}$ to form an ohmic contact. Experimental results show that a smooth surface can be obtained and results in a comparable contact resistance; the contact resistivity of a wafer processed using ion implantation/laser annealing technology is shown in Figure 16 [86].

(a)

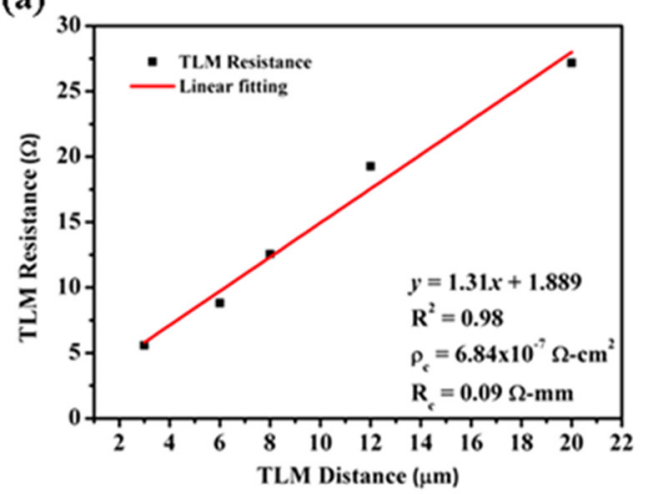

(b)

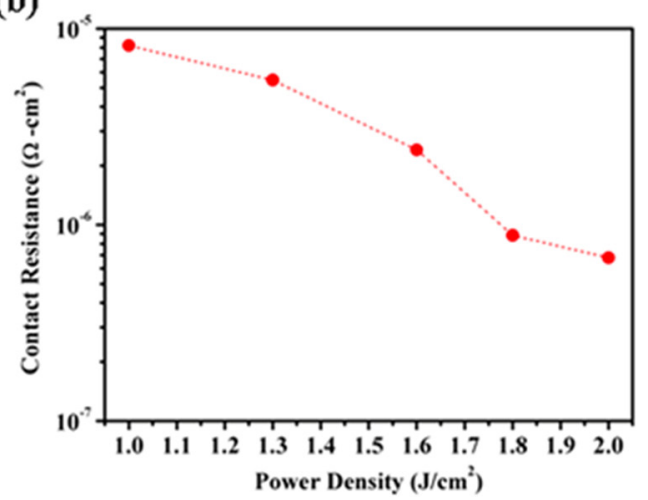

Figure 16. (a) The contact resistance of implanted sample pulsed laser annealing shows a low contact resistance of $6.84 \times 10^{-7} \Omega \mathrm{cm}^{2}$. (b) The contact resistance under different power densities of pulsed laser annealing [86]. (Data from [86]).

\subsection{Metal-Insulator-Semiconductor (MIS) Gate}

The traditional gate process of GaN HEMTs uses a Schottky metal to modulate the 2DEG in the channel. As mentioned earlier, Ni/Au is the most commonly used Schottky gate metal. For $\mathrm{Au}$-free CMOS-compatible processes, a CMOS-compatible high-k gate dielectric, such as $\mathrm{CVD}$-deposited $\mathrm{SiN}$, atomic layer deposition (ALD)-deposited aluminum oxide $\left(\mathrm{Al}_{2} \mathrm{O}_{3}\right)$, or hafnium oxide $\left(\mathrm{HfO}_{2}\right)$, is placed between the $\mathrm{AlGaN}$ barrier layer and the gate metal to form an MIS-HEMT structure to better control the gate leakage current $[87,88]$. With proper surface treatment, the metal-insulator-semiconductor (MIS) gate shows good stability, and it can provide additional protection to the device surface. Figure 17 shows the device structure of a SiN gate MIS-HEMT and the low hysteresis $\mathrm{C}-\mathrm{V}$ behavior of the gate. 
It was also reported that low-temperature deposited $\mathrm{SiN}_{\mathrm{X}}$ combined with high-temperature deposited LPCVD SiN can form a robust MIS gate for GaN power HEMT application [89].
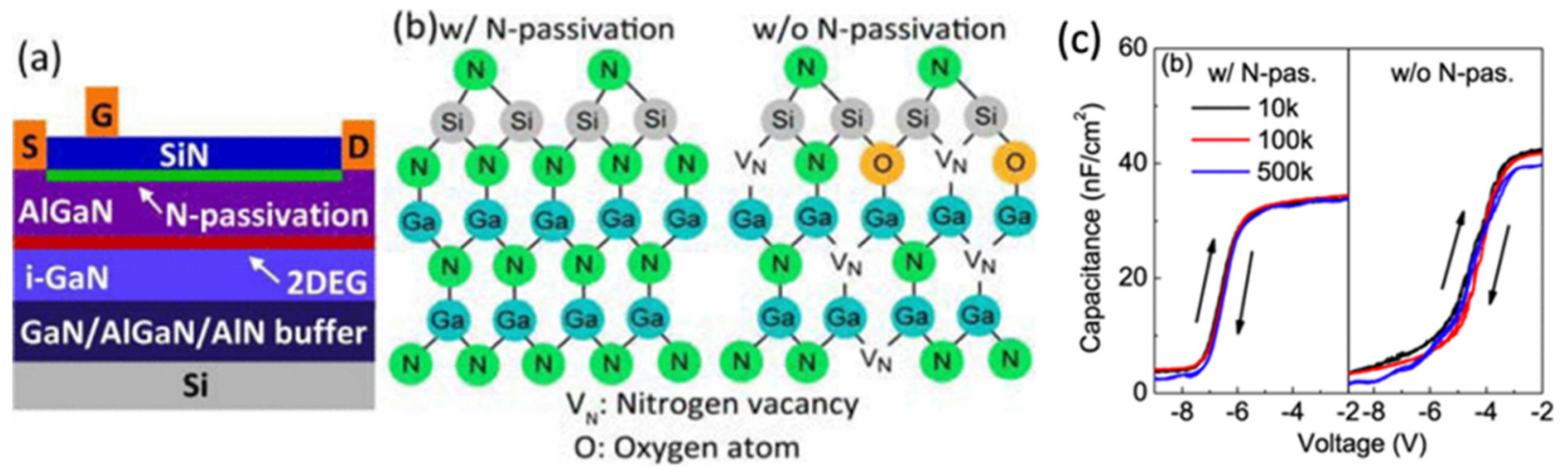

Figure 17. (a) Cross-section of the AlGaN/GaN HEMT with $\mathrm{N}$ passivation and $20 \mathrm{~nm} \mathrm{SiN}$ gate dielectric layer. (b) Schematic of the atomic arrangement at SiN/GaN interface with and without N passivation. (c) C-V characteristics of SiN/GaN MIS capacitor with and without $\mathrm{N}$ passivation at different frequencies varying from 10 to $500 \mathrm{kHz}$ [87]. Figure reproduced with permission from IEEE Electron Device Lett.

Recently, Intel reported the fabrication of an enhancement-mode (e-mode) GaN MOSHEMT with an $\mathrm{AlN} / \mathrm{Al}_{2} \mathrm{O}_{3} / \mathrm{HfO}_{2}$ composite high-K gate dielectric which shows an outstanding $\mathrm{f}_{\mathrm{T}} / \mathrm{f}_{\mathrm{MAX}}$ of $200 \mathrm{GHz} / 300 \mathrm{GHz}$, as mentioned in Section 1.1. These results show that the GaN MOS-HEMT is attractive for realizing energy-efficient, compact voltage regulators and RF power amplifiers for mobile systems on a chip (SoCs) $[24,33]$, as shown in Figure 18.

(a)

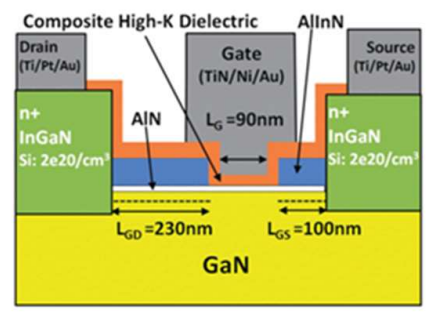

(b)

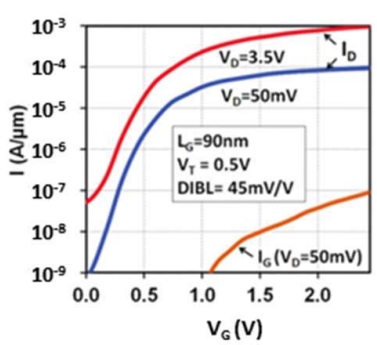

(c)

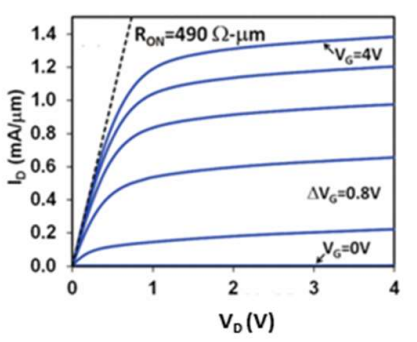

Figure 18. (a) Schematic of the e-mode high-K GaN MOS-HEMT. (b) $\mathrm{I}_{\mathrm{D}}-\mathrm{V}_{\mathrm{G}}$ of the $\mathrm{L}_{\mathrm{G}}=90$ nm e-mode GaN MOS-HEMT showing low $\mathrm{I}_{\mathrm{OFF}}=70 \mathrm{nA} / \mu \mathrm{m}\left(\right.$ at $\left.\mathrm{V}_{\mathrm{G}}=0 \mathrm{~V}, \mathrm{~V}_{\mathrm{D}}=3.5 \mathrm{~V}\right)$, and (c) $\mathrm{I}_{\mathrm{D}}-\mathrm{V}_{\mathrm{D}}$ of the same device showing low on-resistance of $\mathrm{R}_{\mathrm{ON}}=490 \Omega \mu \mathrm{m}$ [24]. Figure reproduced with permission from IEEE 2015 Symposium on VLSI Technology.

\section{Recent Trend in Power GaN}

Applications in power electronics represent the largest market for GaN electronic devices currently. Major trends in the developments for $\mathrm{GaN}$ power devices are $\mathrm{p}-\mathrm{GaN}$ HEMTs for enhancement-mode (E-mode) operation and GaN-on-GaN technology for higher operating voltages. The breakdown voltages for $\mathrm{p}$-GaN HEMTs and vertical GaNon-GaN devices have exceeded $1000 \mathrm{~V}\left(@ \mathrm{R}_{\mathrm{on}, \mathrm{sp}}\right.$ of $\left.2 \mathrm{~m} \Omega \mathrm{cm}^{2}\right)$ and $1.5 \mathrm{kV}\left(@ \mathrm{R}_{\mathrm{on}, \mathrm{sp}}\right.$ of $1 \mathrm{~m} \Omega$ $\left.\mathrm{cm}^{2}\right)$, respectively. We will describe these trends in the following paragraphs.

\section{1. $p-G a N$ Technology}

As stated in Section 1, the presence of a 2DEG in a high-electron mobility channel makes the GaN HEMT a normally on device. In the case of power switching applications, a normally on (depletion mode) GaN HEMT is less desirable than a normally off (enhancement-mode) GaN HEMT due to the fail-safe operation of the former and simpler gate control of the latter. A single-chip e-mode GaN HEMT can be fabricated using 
p-GaN gate [90-94], gate recess [94-96], or plasma treatment techniques [97,98]. In terms of performance, manufacturability, and reliability, the $\mathrm{p}-\mathrm{GaN}$ gate HEMT showed a good balance which has resulted in the first commercialization of single-chip e-mode GaN devices [99-101].

The cross-sectional device structure of the $\mathrm{p}-\mathrm{GaN}$ gate HEMT is shown in Figure 19a [102]. The band structures of normally on AlGaN/GaN HEMTs and normally off p-GaN/AlGaN/GaN HEMTs are shown in Figure 19b,c [99]. The high-electron mobility 2DEG channel is depleted at a zero-bias condition in the case of the p-GaN gate HEMT as the conduction band energy of $\mathrm{AlGaN}$ is lifted due to the presence of the $\mathrm{p}-\mathrm{GaN}$ layer. The device characteristics of the $\mathrm{p}-\mathrm{GaN}$ gate HEMT including $\mathrm{V}_{\mathrm{TH}}$, the $\mathrm{V}_{\mathrm{GS}}$ limitation, and the gate leakage current $\left(\mathrm{I}_{\mathrm{GSS}}\right)$ depend on the structure of the gate stack which could vary according to different manufacturers [98-102]. Table 2 shows the values of gate characteristics of different $\mathrm{p}-\mathrm{GaN}$ devices that have emerged recently in the market [102].

(a)

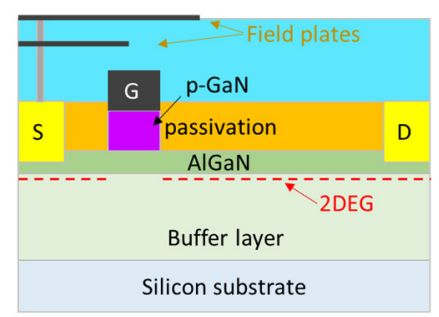

(b)

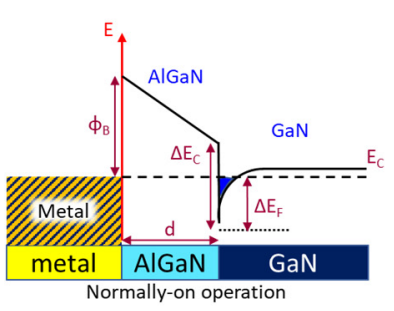

(c)

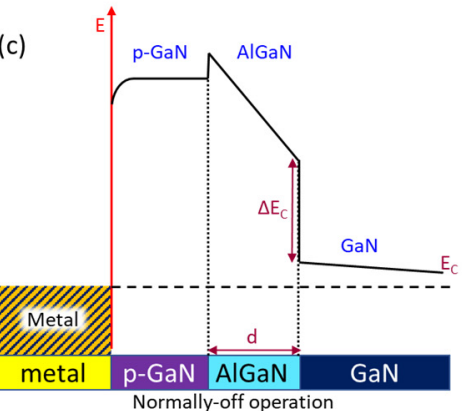

Figure 19. (a) Cross-sectional schematic of p-GaN gate HEMT [102] and (b) schematic of the operation principle of the normally on HEMT and (c) normally off HEMT [99]. (Data from [99,102]).

Table 2. Gate characteristic of different p-GaN devices [102].

\begin{tabular}{ccccc}
\hline Manufacturer & $\mathbf{V}_{\mathbf{T H}}(\mathbf{V})$ & $\begin{array}{c}\mathbf{I}_{\mathbf{D}} / \mathbf{I}_{\mathbf{G}} \text { at } \\
\mathbf{V}_{\mathbf{G S}}=\mathbf{6} \mathbf{V}\end{array}$ & $\begin{array}{c}\mathbf{V G S}_{\min }(\mathbf{V}) / \\
\mathbf{V G S}_{\max }(\mathbf{V})\end{array}$ & $\begin{array}{c}\text { Gate Drive } \\
\text { Voltage(V) }\end{array}$ \\
\hline EPC & 1.4 & $10^{3}-10^{4}$ & $-4 / 6$ & $4-5$ \\
Panasonic & 1.2 & $10^{2}-10^{3 *}$ & $-10 / 4.5$ & $3-5$ \\
GaN Systems & 1.3 & $10^{5}-10^{6}$ & $-10 / 7$ & $5-6.5$ \\
IMEC & $\sim 2.0$ & $10^{5}-10^{10}$ & $-/<12$ & - \\
FBH Berlin & $\sim 1.0$ & $10^{3}-10^{4}$ & $-/ \sim 7$ & 5 \\
\hline
\end{tabular}

${ }^{*}$ Data obtained under $\mathrm{V}_{\mathrm{GS}}=4.5 \mathrm{~V}$, the maximum allowable gate voltage for the Panasonic device.

To effectively deplete the 2DEG channel at $\mathrm{V}_{\mathrm{G}}=0$, the typical AlGaN thickness is $10 \sim 15 \mathrm{~nm}$, and the thickness of the $\mathrm{p}-\mathrm{GaN}$ gate is around $50 \sim 100 \mathrm{~nm}$. The typical p-type dopant for the $\mathrm{p}-\mathrm{GaN}$ (or $\mathrm{p}-\mathrm{AlGaN}$ ) gate is $\mathrm{Mg}$ with a doping concentration of $10^{18} \sim 10^{19} \mathrm{~cm}^{-3}$. Two major process issues are critical for the $\mathrm{p}-\mathrm{GaN}$ gate HEMT device. The first is the selective etch to remove $\mathrm{p}-\mathrm{GaN}$ from areas other than gates. Plasma damage at the recessed GaN surface can cause a problem of reliability. The other issue is the higher gate leakage. Since the $\mathrm{p}-\mathrm{GaN}$ gate is under a high electric field at both positive and negative gate voltages, when the gate voltage is positive, it is depleted and stressed from the gate metal side. When the gate voltage is negative, it is depleted and stressed from the channel side. Therefore, the $\mathrm{p}-\mathrm{GaN}$ epitaxy quality and $\mathrm{p}-\mathrm{GaN} /$ metal interface have to be very robust to avoid a larger gate leakage under high-voltage stress [99].

\subsection{GaN-on-GaN Technology}

At present, the lateral heterojunction AlGaN/GaN HEMT grown on the Si substrate dominates the development of commercial $\mathrm{GaN}$ power electronic devices (up to $10 \mathrm{~kW}$ ) [89]. Lateral devices have shown great potential and are becoming mature [95,103-105], whereas vertical topologies are still in their infancy [106]. However, lateral devices become unap- 
pealing in both cost and manufacturability when the power is very high since it requires a large chip area. To manufacture such high-power devices, vertical topologies are preferred as the chip areas of the devices are smaller than lateral devices owing to vertical devices' ability to withstand the high blocking voltage in the vertical direction into the bulk material.

Unlike lateral devices being grown on $\mathrm{SiC}$ or Si substrates, vertical devices need to be grown on GaN bulk substrates. One typical vertical GaN-on-GaN HEMT device is the current aperture vertical electron transistor (CAVET) [107] shown in Figure 20a. The 2D electron gas channel formed at the interface between $\mathrm{AlGaN}$ and $\mathrm{GaN}$ is used in conjunction with the bulk GaN drift region to achieve low on-resistance. Since the blocking voltage of the device is sustained in a vertical direction into the bulk of the device, the breakdown voltage at the same specific current can be much higher than the HEMT. In this type of device, planar gates control the electron flow in the 2DEG channel, and electrons will then flow vertically towards the $\mathrm{n}-\mathrm{GaN}$ drift region through a conductive aperture between the current blocking layers (CBLs), thereby holding the blocking voltage into the device bulk. Another type of vertical GaN device is the vertical GaN trench MOSFET [108]. As depicted in Figure 20b, the gate trench is buried into the p-type channel layer. The inversion channel is formed at the sidewall of the trench gate during the "on" state. Then, the thick bulk n-drift region conducts the current to the bottom drain electrode. As mentioned previously, such types of devices have been shown to sustain a voltage above $1.5 \mathrm{kV}$. The requirement of extensive passivation and field planting in a lateral device such as an HEMT was eliminated in the case of the vertical device due to the presence of a high electric field inside the bulk which also alleviates current collapse due to surface traps.

(a)

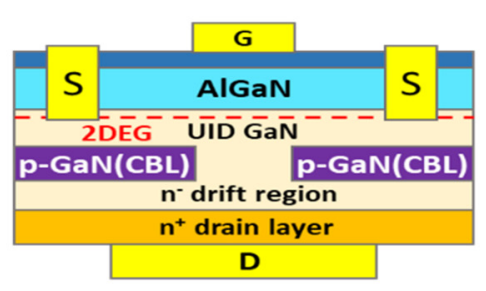

(b)

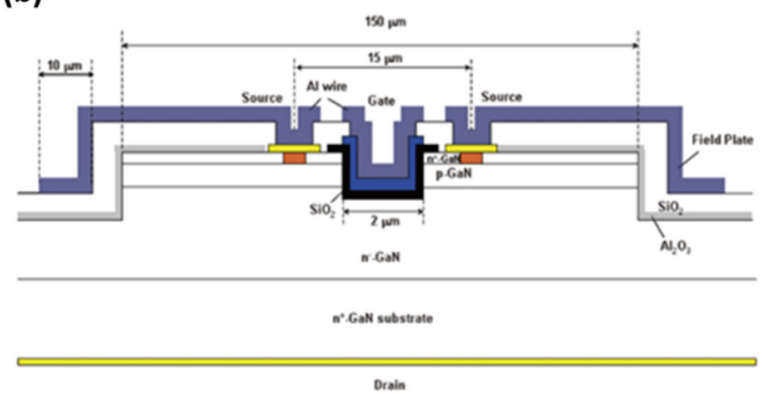

Figure 20. Cross-sectional structure of (a) CAVET [107] and (b) vertical GaN trench MOSFET [108]. Figure reproduced with permission from Japan Society of Applied Physics.

\section{Conclusions}

In the past decade, the wide application of GaN electronic devices has attracted a lot of attention and has gradually matured. Their applications can range from radio frequency power amplifiers to power electronic systems. Due to their wide range of applications and acceptance in the market, the manufacturing process has also evolved from the traditional Au-based III-V technology to high-volume and high-yield CMOS-compatible technology. Moreover, the development of high-voltage vertical device structures has become a new direction. In this article, we provide a short and comprehensive overview to introduce these important technological developments. Due to important applications for such fifthgeneration mobile communications, wireless high-speed chargers, and electric vehicles, we expect the technology and output value of GaN electronic devices to flourish and grow rapidly in the foreseeable future.

Author Contributions: Data curation, C.L. and Y.-W.H.; project administration, Y.-T.C., L.-H.H. and A.-J.T.; supervision, C.-H.L., H.-C.K. and E.Y.C.; writing-original draft, A.-C.L. and P.-T.T.; writing-review and editing, T.W. All authors have read and agreed to the published version of the manuscript. 
Funding: Ministry of Science and Technology, Taiwan (107-2221-E-009-113-MY3, 108-2221-E-009-113MY3).

Institutional Review Board Statement: Not applicable.

Informed Consent Statement: Not applicable.

Data Availability Statement: Not applicable.

Acknowledgments: The authors would like to thank the Industrial Technology Research Institute, Taiwan Semiconductor Research Institute and the Semiconductor Research Center, Hon Hai Research Institute, for the helpful discussion.

Conflicts of Interest: The authors declare no conflict of interest.

\section{References}

1. Zhang, Y.; Singh, J. Charge control and mobility studies for an AlGaN/GaN high electron mobility transistor. J. Appl. Phys. 1999, 85, 587-594. [CrossRef]

2. Millan, J.; Godignon, P.; Perpina, X.; Perez-Tomas, A.; Rebollo, J. A survey of wide bandgap power semiconductor devices. IEEE Trans. Power Electron. 2014, 29, 2155-2163. [CrossRef]

3. Mimura, T.; Hiyamizu, S.; Fujii, T.; Nanbu, K. A new field effect transistor with selectively doped GaAs/n-Al $\mathrm{Ga}_{1-\mathrm{x}} \mathrm{As}$ heterojunctions. Jpn. J. Appl. Phys. 1980, 19, L225-L227. [CrossRef]

4. Mimura, T. Mobile phones, satellite TV receivers and radar equipment. Fujitsu Sci. Tech. J. 2018, 54, 3-8.

5. Touhidul Islam, A.Z.M.; Hatta, K.; Murakoshi, N.; Fukuda, T.; Takada, T.; Itatani, T.; Kamata, N. Detection of NRR Centers in InGaAs/AlGaAs HEMTs: Two-Wavelength Excited Photoluminescence Studies. Glob. Sci. Technol. J. 2013, 1, 1-11.

6. Del Alamo, J.A. The high electron mobility transistor at 30: Impressive accomplishments and exciting prospects. In Proceedings of the 2011 International Conference on Compound Semiconductor Manufacturing Technology, Indian Wells, CA, USA, 16-19 May 2011.

7. Khan, M.A.; Van Hove, J.M.; Kuznia, J.N.; Olson, D.T. High electron mobility GaN/AlxGa1-xN heterostructures grown by low-pressure metalorganic chemical vapor deposition. Appl. Phys. Lett. 1991, 58, 2408-2410. [CrossRef]

8. Asif Khan, M.; Kuznia, J.N.; Bhattarai, A.R.; Olson, D.T. Metal semiconductor field effect transistor based on single crystal GaN. Appl. Phys. Lett. 1993, 62, 1786-1787. [CrossRef]

9. Asif Khan, M.; Bhattarai, A.; Kuznia, J.N.; Olson, D.T. High electron mobility transistor based on a GaN-AlxGa1-xN heterojunction. Appl. Phys. Lett. 1993, 63, 1214-1215. [CrossRef]

10. Mitani, E.; Haematsu, H.; Yokogawa, S.; Nikaido, J.; Tateno, Y. Mass-Production of High-Voltage GaAs and GaN Devices. In Proceedings of the CS Mantech Conference, Vancouver, BC, Canada, 24-27 April 2006.

11. Kikkawa, T. Highly Reliable $250 \mathrm{~W}$ GaN high electron mobility transistor power amplifier. Jpn. J. Appl. Phys. 2005, 44, 4896-4901. [CrossRef]

12. Wakejima, A.; Matsunaga, K.; Okamoto, Y.; Ota, K.; Ando, Y.; Nakayama, T.; Miyamoto, H. 370-W Output Power GaN-FET Amplifier with Low Distortion for W-CDMA Base Stations. In Proceedings of the 2006 IEEE MTT-S International Microwave Symposium Digest, San Franmcisco, CA, USA, 11-16 June 2006; pp. 1360-1363.

13. Kikkawa, T.; Maniwa, T.; Hayashi, H.; Kanamura, M.; Yokokawa, S.; Nishi, M.; Adachi, N.; Yokoyama, M.; Tateno, Y.; Joshin, K. An over 200-W output power GaN HEMT push-pull amplifier with high reliability. In Proceedings of the 2004 IEEE MTT-S International Microwave Symposium Digest (IEEE Cat. No.04CH37535), Fort Worth, TX, USA, 6-11 June 2004; pp. $1347-1350$.

14. Zhang, N.Q.; Moran, B.; DenBaars, S.P.; Mishra, U.K.; Wang, X.W.; Ma, T.P. Kilovolt AlGaN/GaN HEMTs as switching devices. Phys. Status Solidi A Appl. Res. 2001, 188, 213-217. [CrossRef]

15. Visalli, D.; Van Hove, M.; Derluyn, J.; Degroote, S.; Leys, M.; Cheng, K.; Germain, M.; Borghs, G. AlGaN/GaN/AlGaN double heterostructures on silicon substrates for high breakdown voltage field-effect transistors with low on-resistance. Jpn. J. Appl. Phys. 2009, 48, 04C101. [CrossRef]

16. Amano, H.; Baines, Y.; Beam, E.; Borga, M.; Bouchet, T.; Chalker, P.R.; Charles, M.; Chen, K.J.; Chowdhury, N.; Chu, R.; et al. The 2018 GaN power electronics roadmap. J. Phys. D Appl. Phys. 2018, 51, 163001. [CrossRef]

17. Mishra, U.K.; Parikh, P.; Wu, Y.-F. AlGaN/GaN HEMTs-an overview of device operation and applications. Proc. IEEE 2002, 90, 1022-1031. [CrossRef]

18. Qin, H.; Kuang, T.; Luan, X.; Li, W.; Xiao, J.; Zhang, P.; Yang, D.; Zhang, G. Influence of Pressure on the Mechanical and Electronic Properties of Wurtzite and Zinc-Blende GaN Crystals. Crystals 2018, 8, 428. [CrossRef]

19. He, X.-G.; Zhao, D.-G.; Jiang, D.-S. Formation of two-dimensional electron gas at AlGaN/GaN heterostructure and the derivation of its sheet density expression. Chin. Phys. B 2015, 24, 067301. [CrossRef]

20. Kuzmik, J. Power electronics on InAIN/(In)GaN: Prospect for a record performance. IEEE Electron Device Lett. 2001, $22,510-512$. [CrossRef]

21. Xie, J.; Ni, X.; Wu, M.; Leach, J.H.; Özgür, Ü.; Morkoç, H. High electron mobility in nearly lattice-matched AlInN/AlN/GaN heterostructure field effect transistors. Appl. Phys. Lett. 2007, 91, 132116. [CrossRef] 
22. Arteev, D.S.; Sakharov, A.V.; Zavarin, E.E.; Lundin, W.V.; Smirnov, A.N.; Davydov, V.Y.; Yagovkina, M.A.; Usov, S.O.; Tsatsulnikov, A.F. Investigation of Statistical Broadening in InGaN Alloys. J. Phys. Conf. Ser. 2018, 1135, 012050. [CrossRef]

23. Iucolano, F.; Boles, T. GaN-on-Si HEMTs for wireless base stations. Mater. Sci. Semicond. Process. 2019, 98, 100-105. [CrossRef]

24. Then, H.W.; Chow, L.A.; Dasgupta, S.; Gardner, S.; Radosavljevic, M.; Rao, V.R.; Sung, S.H.; Yang, G.; Chau, R.S. High-performance low-leakage enhancement-mode high-K dielectric GaN MOSHEMTs for energy-efficient, compact voltage regulators and RF power amplifiers for low-power mobile SoCs. In Proceedings of the 2015 Symposium on VLSI Technology (VLSI Technology), Kyoto, Japan, 16-18 June 2015; pp. T202-T203.

25. Han, K.; Yang, Y.; You, C.J.; Zhu, X.; Du, X. Reconfigurable continuous Class-F power amplifier using tunable output matching network. In Proceedings of the 17th IEEE International Conference on Communication Technology(ICCT 2017), Chengdu, China, 27-30 October 2017; pp. 1201-1204.

26. Saad, P.; Piazzon, L.; Colantonio, P.; Moon, J.; Giannini, F.; Andersson, K.; Kim, B.; Fager, C. Multi-band/multi-mode and efficient transmitter based on a Doherty Power Amplifier. In Proceedings of the 2012 42nd European Microwave Conference, Amsterdam, The Netherlands, 29 October-1 November 2012; pp. 1031-1034. [CrossRef]

27. Kardaras, G.; Lanzani, C. Advanced multimode radio for wireless \& mobile broadband communication. In Proceedings of the 2009 European Wireless Technology Conference, Rome, Italy, 28-29 September 2009; pp. 132-135.

28. Cho, Y.; Kang, D.; Kim, J.; Moon, K.; Park, B.; Kim, B. Linear doherty power amplifier with an enhanced back-off efficiency mode for handset applications. IEEE Trans. Microw. Theory Tech. 2014, 62, 567-578. [CrossRef]

29. Madero-Ayora, M.J.; Allegue-Martínez, M.; García, J.Á.; Reina-Tosina, J.; Crespo-Cadenas, C. Linearization and EVM enhancement of an efficient class J amplifier for 3G and 4G mobile communication signals. In Proceedings of the 2012 Workshop on Integrated Nonlinear Microwave and Millimetre-Wave Circuits: INMMIC, Dublin, Ireland, 3-4 September 2012; pp. 1-3. [CrossRef]

30. Westberg, E.; Staudinger, J.; Annes, J.; Shilimkar, V. 5G Infrastructure RF Solutions: Challenges and Opportunities. IEEE Microw. Mag. 2019, 20, 51-58. [CrossRef]

31. Shinohara, K. Chapter Four-II-Nitride millimeter wave transistors. In Semiconductors and Semimetals; Chu, R., Shinohara, K., Eds.; Elsevier: Amsterdam, The Netherlands, 2019; Volume 102, pp. 141-184.

32. Shinohara, K.; Regan, D.C.; Tang, Y.; Corrion, A.L.; Brown, D.F.; Wong, J.C.; Robinson, J.F.; Fung, H.H.; Schmitz, A.; Oh, T.C.; et al Scaling of GaN HEMTs and schottky diodes for submillimeter-wave MMIC applications. IEEE Trans. Electron Devices 2013, 60, 2982-2996. [CrossRef]

33. Then, H.W.; Radosavljevic, M.; Desai, N.; Ehlert, R.; Hadagali, V.; Jun, K.; Koirala, P.; Minutillo, N.; Kotlyar, R.; Oni, A.; et al. Advances in Research on 300mm Gallium Nitride-on-Si(111) NMOS Transistor and Silicon CMOS Integration. In Proceedings of the 2020 IEEE International Electron Devices Meeting (IEDM), San Francisco, CA, USA, 12-18 December 2020; pp. 27.3.1-27.3.4.

34. Boles, T. GaN-on-silicon present challenges and future opportunities. In Proceedings of the 2017 12th European Microwave Integrated Circuits Conference (EuMIC), Nuremberg, Germany, 8-10 October 2017; pp. 21-24.

35. Balteanu, F. RF Front End Module Architectures for 5G. In Proceedings of the 2019 IEEE BiCMOS and Compound semiconductor Integrated Circuits and Technology Symposium (BCICTS), Nuremberg, Germany, 3-6 November 2019; pp. 1-8.

36. Chung, J.W.; Hoke, W.E.; Chumbes, E.M.; Palacios, T. AlGaN/GaN HEMT With 300-GHz f $\max$. IEEE Electron Device Lett. 2010, 31, 195-197. [CrossRef]

37. Ćwikliński, M.; Brückner, P.; Leone, S.; Friesicke, C.; Maßler, H.; Lozar, R.; Wagner, S.; Quay, R.; Ambacher, O. D-Band and G-Band High-Performance GaN Power Amplifier MMICs. IEEE Trans. Microw. Theory Tech. 2019, 67, 5080-5089. [CrossRef]

38. Lin, Y.C.; Chen, S.H.; Lee, P.H.; Lai, K.H.; Huang, T.J.; Chang, E.Y.; Hsu, H.-T. Gallium Nitride (GaN) High-Electron-Mobility Transistors with Thick Copper Metallization Featuring a Power Density of $8.2 \mathrm{~W} / \mathrm{mm}$ for Ka-Band Applications. Micromachines 2020, 11, 222. [CrossRef] [PubMed]

39. Then, H.W.; Dasgupta, S.; Radosavljevic, M.; Agababov, P.; Ban, I.; Bristol, R.; Chandhok, M.; Chouksey, S.; Holybee, B.; Huang, C.Y.; et al. 3D heterogeneous integration of high performance high-K metal gate GaN NMOS and Si PMOS transistors on 300mm high-resistivity Si substrate for energy-efficient and compact power delivery, RF (5G and beyond) and SoC applications. In Proceedings of the 2019 IEEE International Electron Devices Meeting (IEDM), San Francisco, CA, USA, 7-11 December 2019; pp. 17.13.11-17.13.14

40. Nune, R.; Anurag, A.; Anand, S.; Chauhan, Y.S. Comparative analysis of power density in Si MOSFET and GaN HEMT based flyback converters. In Proceedings of the 2016 10th International Conference on Compatibility, Power Electronics and Power Engineering (CPE-POWERENG), Bydgoszcz, Poland, 29 June-1 July 2016; pp. 347-352.

41. Roccaforte, F.; Fiorenza, P.; Greco, G.; Nigro, R.L.; Giannazzo, F.; Patti, A.; Saggio, M. Challenges for energy efficient wide band gap semiconductor power devices. Phys. Status Solidi 2014, 211, 2063-2071. [CrossRef]

42. Li, X.; Gao, S.; Zhou, Q.; Liu, X.; Hu, W.; Wang, H. Fabrication and Performance of Ti/Al/Ni/TiN Au-Free Ohmic Contacts for Undoped AlGaN/GaN HEMT. IEEE Trans. Electron Devices 2020, 67, 1959-1964. [CrossRef]

43. Kawanago, T.; Kakushima, K.; Kataoka, Y.; Nishiyama, A.; Sugii, N.; Wakabayashi, H.; Tsutsui, K.; Natori, K.; Iwai, H. Advantage of TiN Schottky gate over conventional Ni for improved electrical characteristics in AlGaN/GaN HEMT. In Proceedings of the 2013 Proceedings of the European Solid-State Device Research Conference (ESSDERC), Bucharest, Romania, 16-20 September 2013; pp. 107-110. 
44. Man Ho, K.; Wong, K.Y.; Lin, Y.S.; Yao, F.W.; Tsai, M.W.; Chang, Y.C.; Chen, P.C.; Su, R.Y.; Wu, C.H.; Yu, J.L.; et al. CMOScompatible GaN-on-Si field-effect transistors for high voltage power applications. In Proceedings of the 2014 IEEE International Electron Devices Meeting, San Francisco, CA, USA, 15-17 December 2014; pp. 17.16.11-17.16.14.

45. Wong, K.Y.R.; Kwan, M.H.; Yao, F.W.; Tsai, M.W.; Lin, Y.S.; Chang, Y.C.; Chen, P.C.; Su, R.Y.; Yu, J.L.; Yang, F.J.; et al. A next generation CMOS-compatible GaN-on-Si transistors for high efficiency energy systems. In Proceedings of the 2015 IEEE International Electron Devices Meeting (IEDM), Wqashington, DC, USA, 7-9 December 2015; pp. 9.5.1-9.5.4.

46. Zhao, D.G.; Xu, S.J.; Xie, M.H.; Tong, S.Y.; Yang, H. Stress and its effect on optical properties of GaN epilayers grown on Si(111), 6H-SiC(0001), and c-plane sapphire. Appl. Phys. Lett. 2003, 83, 677-679. [CrossRef]

47. Nakamura, S. GaN Growth Using GaN Buffer Layer. Jpn. J. Appl. Phys. 1991, 30, L1705-L1707. [CrossRef]

48. Selvaraj, S.L.; Watanabe, A.; Wakejima, A.; Egawa, T. 1.4-kV Breakdown Voltage for AlGaN/GaN High-Electron-Mobility Transistors on Silicon Substrate. IEEE Electron Device Lett. 2012, 33, 1375-1377. [CrossRef]

49. Rowena, I.B.; Selvaraj, S.L.; Egawa, T. Buffer Thickness Contribution to Suppress Vertical Leakage Current With High Breakdown Field (2.3 MV/cm) for GaN on Si. IEEE Electron Device Lett. 2011, 32, 1534-1536. [CrossRef]

50. Tsuchiya, T.; Kitatani, T.; Terano, A.; Mochizuki, K. Interdiffusion of magnesium and iron dopants in gallium nitride. Jpn. J. Appl. Phys. 2015, 54, 035502. [CrossRef]

51. Li, X.; Bergsten, J.; Nilsson, D.; Danielsson, Ö.; Pedersen, H.; Rorsman, N.; Janzén, E.; Forsberg, U. Carbon doped GaN buffer layer using propane for high electron mobility transistor applications: Growth and device results. Appl. Phys. Lett. 2015, 107, 262105. [CrossRef]

52. Villamin, M.E.; Kondo, T.; Iwata, N. Effect of C- and Fe-doped GaN buffer on AlGaN/GaN high electron mobility transistor performance on GaN substrate using side-gate modulation. Jpn. J. Appl. Phys. 2021, 60, Sbbd17. [CrossRef]

53. Kato, S.; Satoh, Y.; Sasaki, H.; Masayuki, I.; Yoshida, S. C-doped GaN buffer layers with high breakdown voltages for high-power operation AlGaN/GaN HFETs on 4-in Si substrates by MOVPE. J. Cryst. Growth 2007, 298, 831-834. [CrossRef]

54. Ikeda, N.; Kaya, S.; Li, J.; Kokawa, T.; Satoh, Y.; Katoh, S. High-power AlGaN/GaN HFETs on Si substrates. In Proceedings of the 2010 International Power Electronics Conference-ECCE ASIA, Sapporo, Japan, 21-24 June 2010; pp. 1018-1022.

55. Hilt, O.; Knauer, A.; Brunner, F.; Bahat-Treidel, E.; Würfl, J. Normally-off AlGaN/GaN HFET with p-type Ga Gate and AlGaN buffer. In Proceedings of the 2010 22nd International Symposium on Power Semiconductor Devices \& IC's (ISPSD), Hiroshima, Japan, 6-10 June 2010; pp. 347-350.

56. Heuken, L.; Kortemeyer, M.; Ottaviani, A.; Schröder, M.; Alomari, M.; Fahle, D.; Marx, M.; Heuken, M.; Kalisch, H.; Vescan, A.; et al. Analysis of an AlGaN/AlN super-lattice buffer concept for 650-V low-dispersion and high-reliability GaN HEMTs. IEEE Trans. Electron Devices 2020, 67, 1113-1119. [CrossRef]

57. Amano, H.; Iwaya, M.; Kashima, T.; Katsuragawa, M.; Akasaki, I.; Han, J.; Hearne, S.; Floro, J.A.; Chason, E.; Figiel, J. Stress and defect control in gan using low temperature interlayers. Jpn. J. Appl. Phys. 1998, 37, L1540-L1542. [CrossRef]

58. Zhou, L.; Smith, D.J.; McCartney, M.R.; Katzer, D.S.; Storm, D.F. Observation of vertical honeycomb structure in InAlN/GaN heterostructures due to lateral phase separation. Appl. Phys. Lett. 2007, 90, 081917. [CrossRef]

59. Kotani, J.; Yamada, A.; Ishiguro, T.; Tomabechi, S.; Nakamura, N. Direct observation of nanometer-scale gate leakage paths in AlGaN/GaN and InAlN/AlN/GaN HEMT structures. Phys. Status Solidi 2016, 213, 883-888. [CrossRef]

60. Ganguly, S.; Konar, A.; Hu, Z.; Xing, H.; Jena, D. Polarization effects on gate leakage in InAlN/AlN/GaN high-electron-mobility transistors. Appl. Phys. Lett. 2012, 101, 253519. [CrossRef]

61. Greco, G.; Iucolano, F.; Roccaforte, F. Ohmic contacts to Gallium Nitride materials. Appl. Surf. Sci. 2016, 383, 324-345. [CrossRef]

62. Luther, B.P.; Mohney, S.E.; Jackson, T.N.; Asif Khan, M.; Chen, Q.; Yang, J.W. Investigation of the mechanism for Ohmic contact formation in $\mathrm{Al}$ and Ti/Al contacts ton-type GaN. Appl. Phys. Lett. 1997, 70, 57-59. [CrossRef]

63. Yadav, Y.K.; Upadhyay, B.B.; Meer, M.; Bhardwaj, N.; Ganguly, S.; Saha, D. Ti/Au/Al/Ni/Au low contact resistance and sharp edge acuity for highly scalable AlGaN/GaN HEMTs. IEEE Electron Device Lett. 2019, 40, 67-70. [CrossRef]

64. Li, Y.; Ng, G.I.; Arulkumaran, S.; Ye, G.; Liu, Z.H.; Ranjan, K.; Ang, K.S. Investigation of gate leakage current mechanism in AlGaN/GaN high-electron-mobility transistors with sputtered TiN. J. Appl. Phys. 2017, 121, 044504. [CrossRef]

65. Kim, J.K.; Jang, H.W.; Lee, J.-L. Mechanism for Ohmic contact formation of Ti onn-type GaN investigated using synchrotron radiation photoemission spectroscopy. J. Appl. Phys. 2002, 91, 9214-9217. [CrossRef]

66. Chandran, N.; Kolakieva, L.; Kakanakov, R.; Polychroniadis, E.K. The role of the Ti and Mo barrier layer in Ti/Al metallization to AlGaN/GaN heterostructures at identical process conditions: A structural and chemical characterization. Semicond. Sci. Technol. 2015, 30, 115011. [CrossRef]

67. Kolaklieva, L.; Kakanakov, R.; Cimalla, V.; Maroldt, S.; Niebelschutz, F.; Tonisch, K.; Ambacher, O. The role of Ti/A1 ratio in nanolayered ohmic contacts for GaN/AlGaN HEMTs. In Proceedings of the 2008 26th International Conference on Microelectronics, Nis, Serbia, 11-14 May 2008; pp. 221-224.

68. Schmitz, A.C.; Ping, A.T.; Khan, M.A.; Chen, Q.; Yang, J.W.; Adesida, I. Metal contacts to n-type GaN. J. Elec. Mater. 1998, 27, 255-260. [CrossRef]

69. Miura, N.; Nanjo, T.; Suita, M.; Oishi, T.; Abe, Y.; Ozeki, T.; Ishikawa, H.; Egawa, T.; Jimbo, T. Thermal annealing effects on Ni/Au based Schottky contacts on $\mathrm{n}-\mathrm{GaN}$ and $\mathrm{AlGaN} / \mathrm{GaN}$ with insertion of high work function metal. Solid State Electron. 2004, 48, 689-695. [CrossRef] 
70. Chiu, H.-C.; Lin, C.-W.; Lin, C.-K.; Kao, H.-L.; Fu, J.S. Thermal stability investigations of AlGaN/GaN HEMTs with various high work function gate metal designs. Microelectron. Reliab. 2011, 51, 2163-2167. [CrossRef]

71. Lu, C.Y.; Chang, E.Y.; Huang, J.C.; Chang, C.T.; Lee, C.T. Stable AlGaN/GaN high electron mobility transistors with tungsten nitride gate metallisation. Electron. Lett. 2009, 45, 1348. [CrossRef]

72. Jaeger, B.D.; Hove, M.V.; Wellekens, D.; Kang, X.; Liang, H.; Mannaert, G.; Geens, K.; Decoutere, S. Au-free CMOS-compatible AlGaN/GaN HEMT processing on $200 \mathrm{~mm}$ Si substrates. In Proceedings of the 2012 24th International Symposium on Power Semiconductor Devices and ICs, Bruges, Belgium, 3-7 June 2012; pp. 49-52.

73. Warnock, S.; Chen, C.L.; Knechtl, J.; Molnar, R.; Yost, D.R.; Cook, M.; Stull, C.; Johnson, R.; Galbraith, C.; Daulton, J.; et al. InAlN/GaN-on-Si HEMT with $4.5 \mathrm{~W} / \mathrm{mm}$ in a 200-mm CMOS-Compatible MMIC Process for 3D Integration. In Proceedings of the 2020 IEEE/MTT-S International Microwave Symposium (IMS), Los Angeles, CA, USA, 4-6 August 2020; pp. $289-292$.

74. Firrincieli, A.; De Jaeger, B.; You, S.; Wellekens, D.; Van Hove, M.; Decoutere, S. Au-free low temperature ohmic contacts for $\mathrm{AlGaN} / \mathrm{GaN}$ power devices on $200 \mathrm{~mm}$ Si substrates. Jpn. J. Appl. Phys. 2014, 53, 04EF01. [CrossRef]

75. Gong, R.; Wang, J.; Liu, S.; Dong, Z.; Yu, M.; Wen, C.P.; Cai, Y.; Zhang, B. Analysis of surface roughness in Ti/Al/Ni/Au Ohmic contact to AlGaN/GaN high electron mobility transistors. Appl. Phys. Lett. 2010, 97, 062115. [CrossRef]

76. Li, L.; Nomoto, K.; Pan, M.; Li, W.; Hickman, A.; Miller, J.; Lee, K.; Hu, Z.; Bader, S.J.; Lee, S.M.; et al. GaN HEMTs on Si With Regrown Contacts and Cutoff/Maximum Oscillation Frequencies of 250/204 GHz. IEEE Electron Device Lett. 2020, 41, 689-692. [CrossRef]

77. Seo, H.-C.; Chapman, P.; Cho, H.-I.; Lee, J.-H.; Kim, K. Ti-based nonalloyed Ohmic contacts for $\mathrm{Al}_{0.15} \mathrm{Ga}_{0.85} \mathrm{~N} / \mathrm{GaN}$ high electron mobility transistors using regrown $\mathrm{n}+-\mathrm{GaN}$ by plasma assisted molecular beam epitaxy. Appl. Phys. Lett. 2008, $93,102102$. [CrossRef]

78. Dasgupta, S.; Nidhi; Brown, D.F.; Wu, F.; Keller, S.; Speck, J.S.; Mishra, U.K. Ultralow nonalloyed Ohmic contact resistance to self aligned N-polar GaN high electron mobility transistors by $\operatorname{In}(\mathrm{Ga}) \mathrm{N}$ regrowth. Appl. Phys. Lett. 2010, 96, 143504. [CrossRef]

79. Huang, T.; Liu, C.; Bergsten, J.; Jiang, H.; Lau, K.M.; Rorsman, N. Fabrication and improved performance of AlGaN/GaN HEMTs with regrown ohmic contacts and passivation-first process. In Proceedings of the 2016 Compound Semiconductor Week (CSW) [Includes 28th International Conference on Indium Phosphide \& Related Materials (IPRM) \& 43rd International Symposium on Compound Semiconductors (ISCS), Toyama, Japan, 26-30 June 2016; pp. 1-2.

80. Vivona, M.; Greco, G.; Lo Nigro, R.; Bongiorno, C.; Roccaforte, F. Ti/Al/W Ohmic contacts to p-type implanted 4H-SiC. J. Appl. Phys. 2015, 118, 035705. [CrossRef]

81. Zhang, J.; Huang, S.; Bao, Q.; Wang, X.; Wei, K.; Zheng, Y.; Li, Y.; Zhao, C.; Liu, X.; Zhou, Q.; et al. Mechanism of Ti/Al/Ti/W $\mathrm{Au}$-free ohmic contacts to AlGaN/GaN heterostructures via pre-ohmic recess etching and low temperature annealing. Appl. Phys. Lett. 2015, 107, 262109. [CrossRef]

82. Liu, Z.; Sun, M.; Lee, H.-S.; Heuken, M.; Palacios, T. AlGaN/AlN/GaN High-Electron-Mobility Transistors Fabricated with Au-Free Technology. Appl. Phys. Express 2013, 6, 096502. [CrossRef]

83. Hyung-Seok, L.; Dong Seup, L.; Palacios, T. AlGaN/GaN High-Electron-Mobility Transistors Fabricated Through a Au-Free Technology. IEEE Electron Device Lett. 2011, 32, 623-625. [CrossRef]

84. Zhang, J.; Kang, X.; Wang, X.; Huang, S.; Chen, C.; Wei, K.; Zheng, Y.; Zhou, Q.; Chen, W.; Zhang, B.; et al. Ultralow-ContactResistance Au-Free Ohmic Contacts With Low Annealing Temperature on AlGaN/GaN Heterostructures. IEEE Electron Device Lett. 2018, 39, 847-850. [CrossRef]

85. Li, G.; Wang, R.; Guo, J.; Verma, J.; Hu, Z.; Yue, Y.; Faria, F.; Cao, Y.; Kelly, M.; Kosel, T.; et al. Ultrathin Body GaN-on-Insulator Quantum Well FETs With Regrown Ohmic Contacts. IEEE Electron Device Lett. 2012, 33, 661-663. [CrossRef]

86. Tzou, A.-J.; Hsieh, D.-H.; Chen, S.-H.; Li, Z.-Y.; Chang, C.-Y.; Kuo, H.-C. Non-thermal alloyed ohmic contact process of GaN-based HEMTs by pulsed laser annealing. Semicond. Sci. Technol. 2016, 31, 055003. [CrossRef]

87. Liu, S.; Chen, B.; Lin, Y.; Hsieh, T.; Wang, H.; Chang, E.Y. GaN MIS-HEMTs With Nitrogen Passivation for Power Device Applications. IEEE Electron Device Lett. 2014, 35, 1001-1003. [CrossRef]

88. Hsieh, T.; Chang, E.Y.; Song, Y.; Lin, Y.; Wang, H.; Liu, S.; Salahuddin, S.; Hu, C.C. Gate Recessed Quasi-Normally OFF Al2O3/AlGaN/GaN MIS-HEMT With Low Threshold Voltage Hysteresis Using PEALD AlN Interfacial Passivation Layer. IEEE Electron Device Lett. 2014, 35, 732-734. [CrossRef]

89. Chen, K.J.; Häberlen, O.; Lidow, A.; Tsai, C.l.; Ueda, T.; Uemoto, Y.; Wu, Y. GaN-on-Si Power Technology: Devices and applications. IEEE Trans. Electron Devices 2017, 64, 779-795. [CrossRef]

90. Lidow, A.; Strydom, J.; De Rooij, M.; Ma, Y. GaN Transistors for Efficient Power Conversion, 2nd ed.; Wiley: Hoboken, NJ, USA, 2014.

91. Uemoto, Y.; Hikita, M.; Ueno, H.; Matsuo, H.; Ishida, H.; Yanagihara, M.; Ueda, T.; Tanaka, T.; Ueda, D. Gate injection transistor (GIT) - A Normally-Off AlGaN/GaN power transistor using conductivity modulation. IEEE Trans. Electron Devices 2007, 54, 3393-3399. [CrossRef]

92. Badawi, N.; Hilt, O.; Behat-Treidel, E.; Böcker, J.; Würfl, J.; Dieckerhoff, S. Investigation of the dynamic on-state resistance of $600 \mathrm{~V}$ normally-off and normally-on GaN HEMTs. In Proceedings of the 2015 IEEE Energy Conversion Congress and Exposition (ECCE), Montreal, QC, USA, 20-24 September 2015; pp. 913-919.

93. Marcon, D.; Saripalli, Y.N.; Decoutere, S. 200mm GaN-on-Si epitaxy and e-mode device technology. In Proceedings of the 2015 IEEE International Electron Devices Meeting (IEDM), Washington, DC, USA, 7-9 December 2015; pp. 16.12.11-16.12.14. 
94. Miyamoto, H.; Okamoto, Y.; Kawaguchi, H.; Miura, Y.; Nakamura, M.; Nakayama, T.; Masumoto, I.; Miyake, S.; Hirai, T.; Fujita, M.; et al. Enhancement-mode GaN-on-Si MOS-FET using Au-free Si process and its operation in PFC system with high-efficiency. In Proceedings of the 2015 IEEE 27th International Symposium on Power Semiconductor Devices \& IC's (ISPSD), Hong Kong, China, 10-14 May 2015; pp. 209-212.

95. Chu, R.; Corrion, A.; Chen, M.; Li, R.; Wong, D.; Zehnder, D.; Hughes, B.; Boutros, K. 1200-V Normally Off GaN-on-Si Field-Effect Transistors With Low Dynamic on -Resistance. IEEE Electron Device Lett. 2011, 32, 632-634. [CrossRef]

96. Chen, K.J.; Zhou, C. Enhancement-mode AlGaN/GaN HEMT and MIS-HEMT technology. Phys. Status Solidi 2011, $208,434-438$. [CrossRef]

97. Chu, R.; Hughes, B.; Chen, M.; Brown, D.; Li, R.; Khalil, S.; Zehnder, D.; Chen, S.; Williams, A.; Garrido, A.; et al. Normally-Off GaN-on-Si transistors enabling nanosecond power switching at one kilowatt. In Proceedings of the 71st Device Research Conference, Notre Dame, IN, USA, 23-26 June 2013; pp. 199-200.

98. Jones, E.A.; Wang, F.; Ozpineci, B. Application-based review of GaN HFETs. In Proceedings of the 2014 IEEE Workshop on Wide Bandgap Power Devices and Applications, Knoxville, TN, USA, 13-15 October 2014; pp. 24-29.

99. Greco, G.; Iucolano, F.; Roccaforte, F. Review of technology for normally-off HEMTs with p-GaN gate. Mater. Sci. Semicond. Process. 2018, 78, 96-106. [CrossRef]

100. Jiang, H.; Zhu, R.; Lyu, Q.; Lau, K.M. High-Voltage p-GaN HEMTs with off-state blocking capability after gate breakdown. IEEE Electron Device Lett. 2019, 40, 530-533. [CrossRef]

101. Uemoto, Y.; Morita, T.; Ikoshi, A.; Umeda, H.; Matsuo, H.; Shimizu, J.; Hikita, M.; Yanagihara, M.; Ueda, T.; Tanaka, T.; et al. GaN monolithic inverter IC using normally-off gate injection transistors with planar isolation on Si substrate. In Proceedings of the 2009 IEEE International Electron Devices Meeting (IEDM), Baltimore, MD, USA, 7-9 December 2009; pp. 1-4.

102. Wang, H.; Wei, J.; Xie, R.; Liu, C.; Tang, G.; Chen, K.J. Maximizing the Performance of 650-V p-GaN Gate HEMTs: Dynamic RON Characterization and Circuit Design Considerations. IEEE Trans. Power Electron. 2017, 32, 5539-5549. [CrossRef]

103. Dora, Y.; Chakraborty, A.; Mccarthy, L.; Keller, S.; Denbaars, S.P.; Mishra, U.K. High Breakdown Voltage Achieved on AlGaN/GaN HEMTs With Integrated Slant Field Plates. IEEE Electron Device Lett. 2006, 27, 713-715. [CrossRef]

104. Selvaraj, S.L.; Suzue, T.; Egawa, T. Breakdown Enhancement of AlGaN/GaN HEMTs on 4-in Silicon by Improving the GaN Quality on Thick Buffer Layers. IEEE Electron Device Lett. 2009, 30, 587-589. [CrossRef]

105. Lu, B.; Palacios, T. High Breakdown (> 1500V) AlGaN/GaN HEMTs by Substrate-Transfer Technology. IEEE Electron Device Lett. 2010, 31, 951-953. [CrossRef]

106. Chowdhury, S.; Mishra, U.K. Lateral and Vertical Transistors Using the AlGaN/GaN Heterostructure. IEEE Trans. Electron Devices 2013, 60, 3060-3066. [CrossRef]

107. Chowdhury, S.; Swenson, B.L.; Wong, M.H.; Mishra, U.K. Current status and scope of gallium nitride-based vertical transistors for high-power electronics application. Semicond. Sci. Technol. 2013, 28, 074014. [CrossRef]

108. Oka, T.; Ueno, Y.; Ina, T.; Hasegawa, K. Vertical GaN-based trench metal oxide semiconductor field-effect transistors on a free-standing GaN substrate with blocking voltage of 1.6 kV. Appl. Phys. Express 2014, 7, 021002. [CrossRef] 